\title{
Optimizing a Rodent Model of Parkinson's Disease for Exploring the Effects and Mechanisms of Deep Brain Stimulation
}

\author{
Karl Nowak, ${ }^{1}$ Eilhard Mix, ${ }^{1}$ Jan Gimsa, ${ }^{2}$ Ulf Strauss, ${ }^{3}$ Kiran Kumar Sriperumbudur, ${ }^{2}$ \\ Reiner Benecke, ${ }^{1}$ and Ulrike Gimsa ${ }^{4}$ \\ ${ }^{1}$ Department of Neurology, University of Rostock, Gehlsheimer Straße 20, 18147 Rostock, Germany \\ ${ }^{2}$ Institute of Biology, Chair of Biophysics, University of Rostock, Gertrudenstraße 11A, 18157 Rostock, Germany \\ ${ }^{3}$ Cellular Electrophysiology, Institute for Cell Biology and Neurobiology, Center for Anatomy, Charité-Universitaetsmedizin Berlin, \\ Philippstraße 12, 10115 Berlin, Germany \\ ${ }^{4}$ Research Unit Behavioural Physiology, Leibniz Institute for Farm Animal Biology, Wilhelm-Stahl-Allee 2, \\ 18196 Dummerstorf, Germany
}

Correspondence should be addressed to Ulrike Gimsa, gimsa@fbn-dummerstorf.de

Received 15 October 2010; Accepted 28 January 2011

Academic Editor: David S. Park

Copyright ( $) 2011$ Karl Nowak et al. This is an open access article distributed under the Creative Commons Attribution License, which permits unrestricted use, distribution, and reproduction in any medium, provided the original work is properly cited.

\begin{abstract}
Deep brain stimulation (DBS) has become a treatment for a growing number of neurological and psychiatric disorders, especially for therapy-refractory Parkinson's disease (PD). However, not all of the symptoms of PD are sufficiently improved in all patients, and side effects may occur. Further progress depends on a deeper insight into the mechanisms of action of DBS in the context of disturbed brain circuits. For this, optimized animal models have to be developed. We review not only charge transfer mechanisms at the electrode/tissue interface and strategies to increase the stimulation's energy-efficiency but also the electrochemical, electrophysiological, biochemical and functional effects of DBS. We introduce a hemi-Parkinsonian rat model for long-term experiments with chronically instrumented rats carrying a backpack stimulator and implanted platinum/iridium electrodes. This model is suitable for (1) elucidating the electrochemical processes at the electrode/tissue interface, (2) analyzing the molecular, cellular and behavioral stimulation effects, (3) testing new target regions for DBS, (4) screening for potential neuroprotective DBS effects, and (5) improving the efficacy and safety of the method. An outlook is given on further developments of experimental DBS, including the use of transgenic animals and the testing of closed-loop systems for the direct on-demand application of electric stimulation.
\end{abstract}

\section{Introduction}

1.1. History. One of the well-established therapeutic interventions in neurological and psychiatric disorders, especially in the late stages, is the high frequency electrical stimulation of neuronal structures in the depth of the brain, named by convention "deep brain stimulation (DBS)". This method has developed from different lines of experimental and clinical investigations and technical innovations:

(1) stereotactic surgery,

(2) ablative brain surgery with tissue excision, thermocoagulation or cryolesioning,

(3) portable and implantable cardiac pacemakers.
The first experiments with stereotactic interventions in the brain date back to the 1920s when Hess in Zurich stereotactically implanted depth electrodes in freely moving cats. In the 1940s, Spiegel et al. in Philadelphia performed the first stereotactical operations in the human brain [1]. The pioneers of ablative brain surgery were Moniz and Scoville. Both were so-called psychosurgeons who tried to treat psychiatric disorders, mainly schizophrenia, by excising or destroying certain brain areas. Their method went through its ups and downs with the climax being the subsequently obsolete prefrontal leucotomy in the 1930s. However, thalamotomy, pallidotomy, lobectomy, cordotomy, dentatomy, and other ablative operations were also applied to treat movement disorders, pain, and epilepsy. For example, 
in the 1950s, Hassler et al. [2] performed more than 300 stereotactic operations in patients with movement disorders, such as athetosis, torsion dystonia, tremor, and PD. They applied the coagulation of various subcortical, mainly pallidal and thalamic, structures and included acute electric stimulation with different pulse shapes and frequency to ensure an exact location of the electrode tip. Thereby, they found a clear target and frequency dependence of the stimulation effect on tremor, hyperkinesias, and rigidity. For example, stimulation of the inner pallidum with frequencies up to $10 \mathrm{~Hz}$ increased the tremor, but stimulation with frequencies from 25 to $100 \mathrm{~Hz}$ decreased the tremor. With the improvement of surgical techniques and the introduction of implantable pulse generators (Medtronic, Minneapolis, MN, USA) in the 1950s, ablative surgery became a chronic electrical stimulation treatment, and DBS was born. Milestones of its application in central disorders were the therapeutic trials for the treatment of the following:

(1) pain and epilepsy by Bechtereva et al. in Leningrad [3],

(2) torticollis spasmodicus by Mundinger in Freiburg [4],

(3) dyskinesia by Siegfried et al. in Zurich [5],

(4) essential tremor and PD by Benabid et al. in Grenoble [6].

Despite the rapidly increasing application of DBS in clinical practice, its mechanisms of action remain poorly understood. Technical improvements and parameter optimization depend mainly on an empiric trial-and-error strategy. However, the electric stimulation of neurons affected by DBS acts according to the general rule of excitability, that is, according to an exponential strength-duration relationship [7]. Two major parameters characterize this relationship. These parameters were first defined 100 years ago by Lapicque to facilitate the comparison of excitability (excitation thresholds) between different objects [8]. The parameters are "rheobase" and "chronaxie", which are coordinates on the strength-duration curve for a stimulus. In neurons, the rheobase is the minimal current amplitude of an almost infinite duration that triggers an action potential, whereas chronaxie represents the shortest duration of an electrical stimulus having an amplitude equal to twice the minimum amplitude required for excitation. Therefore, the rheobase is half the current that needs to be applied for the duration of chronaxie.

1.2. Current Clinical Application. The spectrum of neuropsychiatric diseases treated by DBS, either routinely or in clinical studies, has expanded very rapidly (for review, see [9-13]). However, only the following 4 indications are approved for treatment with DBS by FDA/CE certification:

(1) essential tremor with stimulation of the ventrointermediate (VIM) thalamic nucleus [14],

(2) PD with stimulation of the subthalamic nucleus (STN) or the globus pallidus internus (GPi), a region that is analogous to the entopeduncular nucleus (EP) of the rat [15],

(3) dystonia with stimulation of the GPi for torticollis spasmodicus and generalized dystonia [16],

(4) treatment-resistant obsessive-compulsive disorder (OCD) with stimulation of the internal capsule anterior limb [17].

For the extension of approved indications for DBS, it is necessary to do the following:

(1) to define new target regions for specific indications,

(2) to optimize electrodes and stimulation parameters for specific target regions.

The largely unsolved questions regarding clinical DBS are the exact mechanisms of action of the method and the guidelines for the selection of optimal electrodes and optimal stimulation parameters. The overall aim is to achieve maximum therapeutic efficacy with a minimum of adverse side effects and energy draw. This requires basic studies under defined and reproducible conditions with repeated access to tissue samples in the neighborhood of the electrode tip, which can only be realized in animal model systems. Because PD occurs worldwide and it is the most frequent degenerative movement disorder, experimental investigations have focused on animal models of this disease [18]. These models have been most commonly established in rodents.

1.3. Animal Models. Animal models for the study of the pathogenetic mechanisms and new therapies for human movement disorders and psychiatric diseases, such as OCD, have traditionally been induced by neurotoxins, acting selectively on neurons affected by human diseases. Examples of the most common toxic models for the study of DBS are the following:

(1) the hemi-PD-like disorder induced in rats or mice by unilateral intracerebral injection of 6-hydroxydopamine (6-OHDA) [19] or a carotid MPTP injection in primates [20],

(2) the PD-like disorder induced by an intravenous injection of 1-methyl-4-phenyl-1,2,3,6-tetrahydropyridine (MPTP) in mice or primates $[21,22]$,

(3) the essential tremor-like disease by the intraperitoneal injection of the monoaminooxidase (MAO)-A inhibitor, harmaline, in mice $[23,24]$,

(4) an OCD-like disease induced by the subcutaneous injection of quinpirole in rats [25-29].

This paper focuses on optimization strategies for DBS using the 6-OHDA-induced hemi-Parkinsonism model in rats; this animal model has several advantages.

(1) The neurotoxin 6-OHDA exerts high selectivity for dopaminergic neurons, which are destroyed by reactive oxygen mechanisms in the substantia nigra pars compacta $(\mathrm{SNc})$ either after a direct injection of 
the toxin into this structure or after its retrograde transport from injected dopaminergic projections in the medial forebrain bundle (MFB) or the striatum (caudate putamen $(\mathrm{CPu})$ of the rat) to the soma in the SNc. Therefore, a central pathophysiological feature of human PD, the selective dopaminergic denervation of the striatum, is reproduced resulting in similar electromyographic and gait abnormalities seen in PD patients [30-33].

(2) This model is the most widely used paradigm for PD research and is exceedingly well characterized on the molecular biological, histological and functional level. It allows for a direct comparison of data with the majority of experimental PD studies worldwide.

(3) The therapeutic effects of DBS on the core symptoms of $\mathrm{PD}$, such as rigidity, hypokinesia, tremor, postural instability, and cognitive impairment, can easily be monitored using a broad spectrum of behavioral tests that can analyze single and complex motor and cognitive functions by investigating a wide variety of behaviors including the following:

(i) drug-induced rotation,

(ii) accelerated rotation on a treadmill,

(iii) ladder rung walking,

(iv) beam balance,

(v) postural balance,

(vi) asymmetric limb use in a transparent cylinder,

(vii) stepping movement,

(viii) lateralized response in a corridor task test,

(ix) free explorative movement in an open field, radial maze, and water maze,

(x) vibrissae-elicited forelimb placing,

(xi) paw reaching or pellet grasping on a staircase,

(xii) attention and impulsivity in a 5-choice serial reaction time recorder.

For details of the 6-OHDA-induced hemi-Parkinsonism model and other relevant animal models of PD, see [34].

To create an optimal experimental design for animal studies and to avoid unnecessary animal experiments with DBS, computational simulation and modeling possess great potential. In silico calculations allow for the prediction of influences of DBS parameter changes on electric field properties with increasing precision, the consequences of electrochemical processes at the interface between the electrodes and surrounding nervous tissue and electrical nerve cell activity.

\section{Numerical Analysis of Electric Field Effects}

To understand the effects of DBS, the question of its mechanism can be addressed at the cellular level by asking what structures are actually being stimulated or inhibited, axons, or cell bodies. This question has already been debated at the time when DBS has first been applied in the clinic
[35]. However, only long after the first successful application of DBS in patients this question became a subject of numerical analysis using finite element modeling $[36,37]$. The numerical analysis of electric field effects aims at describing the distribution of the stimulated neurons around the DBS electrode based on the inhomogeneous current density and field distributions in the stimulated brain tissue. The induced transmembrane potential and, alternatively, the so-called "activation function", are considered the major determinants for neuronal stimulation [38, 39]. A correct description of the distributions of both parameters calls for the invocation of the influence of inhomogeneous and anisotropic brain tissue properties [40, 41]. Anisotropies and inhomogeneities at the structural level are introduced by ionic conductivity and the permittivity patterns in the brain tissue. It can be assumed that membrane structures influence these properties in different ways. Although ion currents will mainly flow in parallel to membrane planes, displacement (capacitive) currents may flow perpendicularly to bridge membranes because of the high area-specific capacitance of these thin layers. Nevertheless, capacitive membrane bridging will probably play a significant role only in the high-frequency components of DBS pulses above $10 \mathrm{kHz}$ [42]. For this reason, it seems justified to consider the anisotropic properties only for ionic currents. Because such properties are hard to obtain, global brain data for the anisotropy of water diffusion obtained from NMR measurements are used to describe the anisotropy of brain tissue [41]. Nevertheless, the frequency-dependent spreading of the stimulation signal in the brain tissue at the cellular level is not easy to describe. Such models require the correct description of cellular geometries and exist for tissues with a much simpler structure, such as the skin [43]. The electrochemical electrode properties, cell membranes, cytoplasmic structures and interstitial media form frequency filters that change the amplitude and frequency spectrum in the stimulated tissue depending on the electrode distance. These properties and the anisotropic properties at the cellular level are usually not considered, mainly because of the differences in the size of the cells and the DBS electrodes. Nevertheless, a major challenge for the transformation of human stimulation conditions into animal models is caused by this size difference. The size influences the maximally applicable voltage (or current) at which membrane poration and tissue damage are still avoided $[44,45]$. In the following discussion, the major relationships of this limiting DBS parameter to the electrode size, medium conductivity, cell constant, and the local shape of the stimulation electrode are considered.

For a cubical cell confined by two square electrodes, the resistance, $R$, is given by Ohm's law when electrode effects are neglected

$$
R=\frac{U}{I}=\frac{d E}{I}=\frac{d E}{i A}
$$

where $U, I, d, E$, and $i$ stand for the voltage across the cell, the current through the cell, the electrode distance and area $\left(A=d^{2}\right)$, and the current density in $\mathrm{A} / \mathrm{m}^{2}$, respectively. 
(Please note that the vectorial properties of the parameters are neglected for simplicity.) The resistance can also be expressed by the cell geometry and the specific conductivity, $\sigma$

$$
R=\frac{d}{\sigma A}=\frac{1}{\sigma \gamma}
$$

with $\gamma=d$ being the cell constant of the cubical cell, that is, the geometry factor relating the electrode impedance to the specific medium conductivity, $\sigma$. Although $\gamma$ has been derived for a cubical chamber, it can easily be generalized to any cell geometry when medium anisotropies and electrode processes are neglected [39]. Combining (1) and (2), we get the general relationship of field strength and current density in a homogeneous medium

$$
E=\frac{i}{\sigma}
$$

In the following discussion, a spherical electrode suspended in an homogeneous medium of conductivity $\sigma$ will be considered. This model correctly describes the influence of electrode size on the cell constant, $\gamma$, and the interrelationships of the applied voltage, electrode current, field strength, and current density at the electrode surface and the distribution of these parameters in the surrounding medium. The resistance of a setup with two concentric spherical electrodes of distance $x$ is (Figure 1)

$$
R=\frac{r_{\mathrm{cnt}}-r_{\mathrm{el}}}{4 \pi \sigma r_{\mathrm{cnt}} r_{\mathrm{el}}}=\frac{x}{4 \pi \sigma\left(r_{\mathrm{el}}+x\right) r_{\mathrm{el}}}
$$

where $r_{\mathrm{cnt}}$ and $r_{\mathrm{el}}$ are the radii of the counter- and the inner electrodes, respectively. The two limiting cases of this model are two electrodes with comparable radii, that is, electrode areas of $A=4 \pi r_{\mathrm{el}}^{2}$ leading to (compare to (2))

$$
R_{\left(r_{\mathrm{cnt}} \approx r_{\mathrm{el}}\right)}=\frac{x}{4 \pi \sigma r_{\mathrm{el}}^{2}}=\frac{x}{\sigma A}
$$

and a counterelectrode at an infinite distance. We obtain

$$
R_{x \rightarrow \propto}=\frac{1}{4 \pi \sigma r_{\mathrm{el}}}=\frac{1}{\sigma \gamma}
$$

with the cell constant of $\gamma=4 \pi r_{\text {el }}$ for a spherical electrode. This situation is comparable to a unipolar stimulation with the counterelectrode being located in the stimulator case.

Applying Ohm's law to (6), expressing the electrode current by the current density at the electrode's surface and using (3) leads to

$$
R_{x \rightarrow \infty}=\frac{1}{4 \pi \sigma r_{\mathrm{el}}}=\frac{U}{4 \pi i_{\mathrm{el}} r_{\mathrm{el}}^{2}}=\frac{U}{4 \pi \sigma E r_{\mathrm{el}}^{2}} .
$$

For the field strength at the surface of the electrode $E_{0}$, we obtain:

$$
E_{0}=\frac{U}{r_{\mathrm{el}}}=\frac{R I}{r_{\mathrm{el}}}=\frac{I}{4 \pi \sigma r_{\mathrm{el}}^{2}}=\frac{i_{0}}{\sigma}
$$

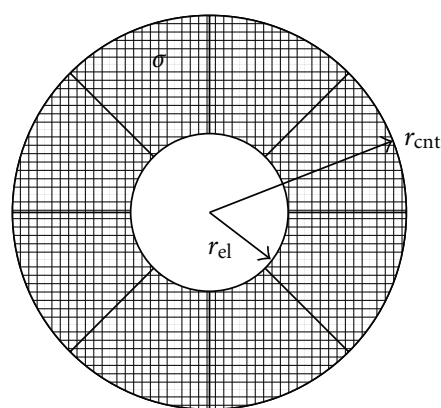

FIGURE 1: Distribution of the electric field between two concentric spherical electrodes. Electric field lines span the distance between the stimulation electrode of radius $r_{\mathrm{el}}$ and the counterelectrode with radius $r_{\mathrm{cnt}}$. The medium between the electrodes has a conductivity of $\sigma$.

Expressing $I$ by the current density at the electrode surface, we obtain (3). The field strength at distance $x$ from the electrode is

$$
E(x)=\frac{r_{\mathrm{el}} U}{\left(r_{\mathrm{el}}+x\right)^{2}}=\frac{I}{4 \pi \sigma\left(r_{\mathrm{el}}+x\right)^{2}} .
$$

Equation (8) shows that not only the voltage or current applied to an electrode but also its surface curvature determines the medium field strength. Assuming that field strength, cell size, and orientation determine the induced transmembrane potential, which is one of the possible determinants of neuronal stimulation, (8) and (9) imply a number of conclusions.

(i) Induced transmembrane potentials above approximately $1 \mathrm{~V}$, which are believed to cause membrane poration and cell damage, may occur especially at small electrodes.

(ii) Nerve tissue in the vicinity of high electrode curvatures, that is, blunt electrode edges, and the like, is especially vulnerable to electric cell damage.

(iii) Assuming that the redox-like processes at the electrode surfaces generate a constant voltage (overpotentials, see [42]) at the electrode-medium interface, the voltage portion required to overcome the overpotentials increases for smaller electrodes. This makes smaller electrodes more vulnerable to the precision of electrode machining, that is, electrode size, metal burs, and the like. Assuming that neurons are stimulated by induced transmembrane potentials in a range from 5 to $500 \mathrm{mV}$, a linear dependence of the induced transmembrane potential on the field strength $[44,45]$ suggests a reach of $10 r_{\mathrm{el}}$ into the tissue.

(iv) Analysis of the inhomogeneous current density distributions at the electrode surfaces allows for the localization of probable hot spots of metal corrosion and the erosion of the insulating parts.

Numerical calculations of electric potentials, electric fields, and current densities around DBS electrodes can be 


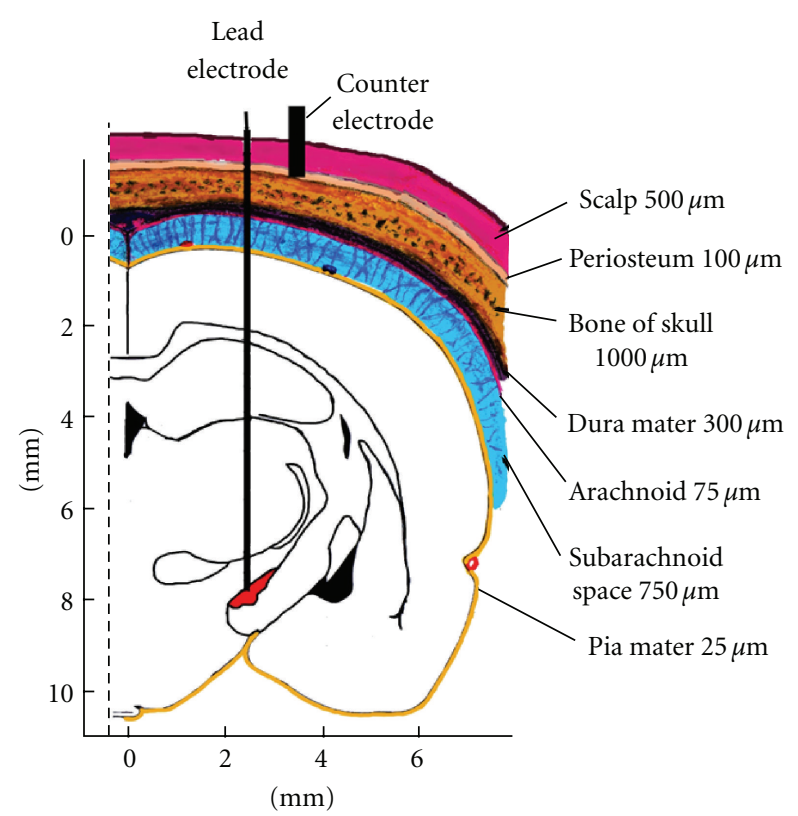

FIGURE 2: Electrode placement in a brain slice of a rat at bregma: $-3.60 \mathrm{~mm} /$ interaural: $5.40 \mathrm{~mm}$ illustrating that the insulated electrode shaft penetrates several layers of different dielectric properties, that is, the scalp, bone of skull, dura mater, subarachnoid space, and brain tissue. For unipolar lead electrodes, the counter electrode is placed subcutaneously directly on the skull at a distance of more than $20 \mathrm{~mm}$. The red structure at the tip of the electrode is the STN.

performed when dimensions and electric properties of the tissues that surround the electrodes are taken into account. Figure 2 shows a schematic frontal view of a brain slice of a rat, where a DBS electrode is placed in the STN.

A simplified numerical model for a unipolar DBS electrode in this brain slice is depicted in Figure 3. It features the major geometric properties of a rat head as shown in Figure 2. Figure 3(a) specifies the dimensions of the model on which numerical calculations with COMSOL based. We differentiated between high density/low conductivity tissue, that is, bone of skull, dura mater and arachnoid, and low density/high conductivity tissue and fluids, that is, pia mater, gray and white matter, and cerebrospinal fluid, which have different electric properties. Because of a lack of data on dielectric properties of rat tissues, the properties of the respective human tissues were assumed at a frequency of $130 \mathrm{~Hz}$ for the simulation in COMSOL. The rectangular DBS stimulation pulse can be modeled by a Fourier series with a basic frequency of $130 \mathrm{~Hz}$. Because the Fourier coefficients of the signal are reduced for frequencies above $3 \mathrm{kHz}$, Table 1 contains values for $130 \mathrm{~Hz}, 1 \mathrm{kHz}$, and $3 \mathrm{kHz}$ ([42]; for reference values see: http://niremf.ifac.cnr.it/tissprop/htmlclie/htmlclie .htm\#atsftag). Figure 3(b) shows the calculated potential distribution around a stimulation electrode for use in a rat model (see Figure 8) across this brain model for an input voltage of $1 \mathrm{~V}$.
Figure 3(b) demonstrates that the potential rapidly drops in the immediate vicinity of the electrode tip. Please note that there is a potential drop at the interface between brain and bone which is hardly visible at this resolution. Figure 4 shows the calculated distributions of electric potential, electric field, and current density around a cylindrical unipolar DBS electrode tip.

Figure 5 presents the comparison of simulated potential distributions between a cylindrical unipolar electrode (radius: $100 \mu \mathrm{m}$; see Figure 8 ) and a spherical unipolar electrode according to Figure 1 with the counterelectrode at an infinite distance. For a high consistency of the analytical and the numerical results and to reproduce the potential distribution around the cylindrical electrode at a distance of $400 \mu \mathrm{m}$, the center of the spherical electrode had to be positioned in the base of the cylinder and its radius had to be adjusted to $\sim 86.6 \mu \mathrm{m}$. The comparison suggests that the presented analytical solution for a unipolar spherical electrode can be used for estimating the field and potential distributions around a stimulating electrode.

Numerical analyses have become very sophisticated in that they nowadays couple finite element models of the electrodes and surrounding medium with cable models of myelinated axons to predict the volume of activated tissue as a function of stimulation parameter settings and electrode design [46]. The combination of numerical modeling and experimental characterization of the voltage distribution generated by DBS in the brain provides information on the quality of the models regarding spatial and temporal characteristics of the voltage distribution generated by DBS electrodes [47]. By increasing the complexity of the model from an electrostatic, homogenous, and isotropic model to one that explicitly incorporates the voltage drop and capacitance of the electrode-electrolyte interface, tissue encapsulation of the electrode, and diffusion-tensor-based 3D-tissue anisotropy and inhomogeneity (see Section 3), it has been shown that the simpler models substantially overestimate the spatial extent of neural activation [48].

\section{Electrochemical Considerations in the Context of DBS}

Electrode processes are inherent when applying an electric field via a metal electrode in contact to an electrolytecontaining medium such as brain tissue. Electrochemists have been dealing with the properties of electrodes and electrode processes beginning in the 19th century [49]. Comprehensive overviews are given in textbooks, for example, Vetter [50] and Atkins [51]. Serious consideration should be given to the choice of electrode materials and stimulation parameters in experimental animal models of DBS. As described above, simply downscaling electrodes designed for use in humans to the size of animal brains is not possible. Most reports on the postmortem analyses of tissue integrity do not find signs of tissue damage after continuous DBS application in patients [52-54]. However, a newer report demonstrates histological alterations induced by electrode implantation and electrical stimulation [55]. 


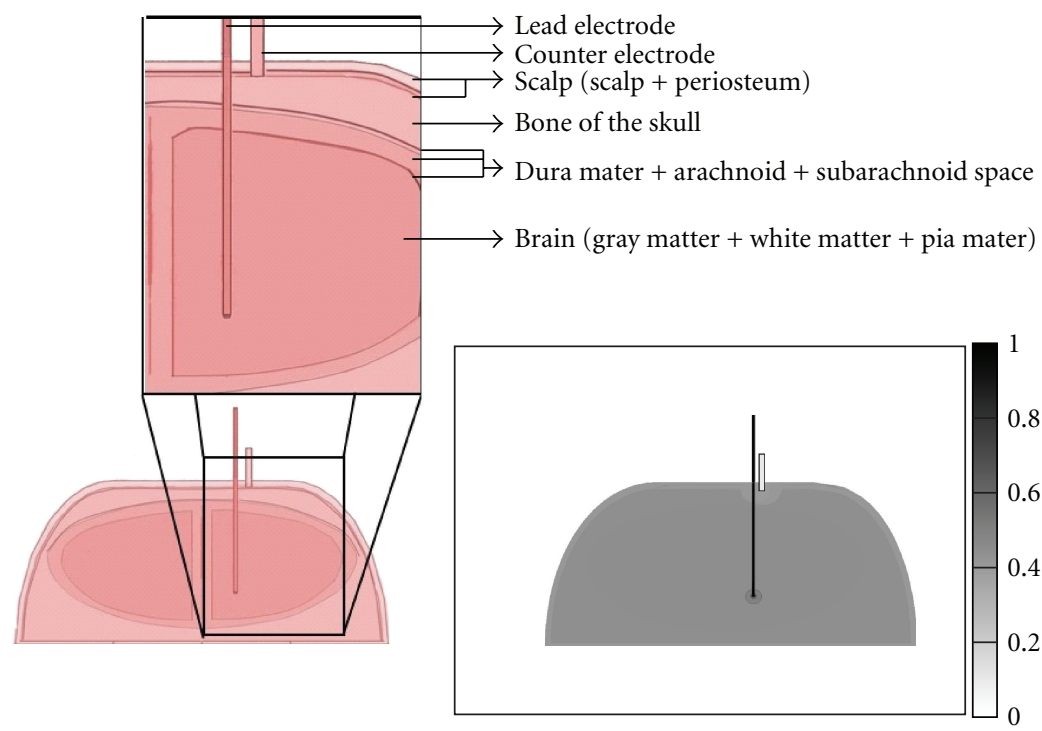

(a)

(b)

FIgure 3: COMSOL simulation. (a) Tissue layers and dimensions for the COMSOL calculation around a DBS electrode (radius: $100 \mu \mathrm{m}$; see Figure 8) in the STN of a rat brain using dimensions depicted in Figure 2. Tissues of similar dielectric properties are summarized by arrows. (b) COMSOL simulation of electric potential in the cross-section depicted in (a). For simplicity reasons, the values of gray matter at $130 \mathrm{~Hz}$ from Table 1 were used for the tissue assumed as "brain".

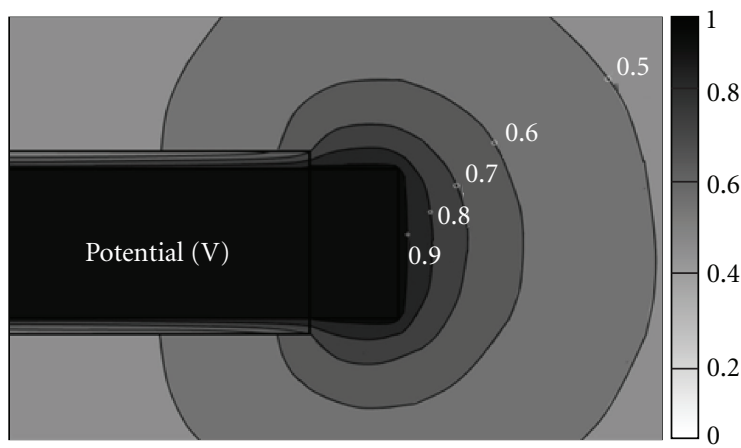

(a)

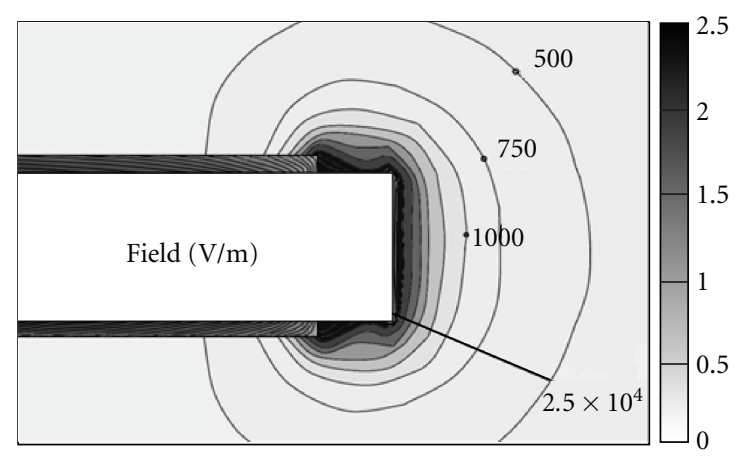

(b)

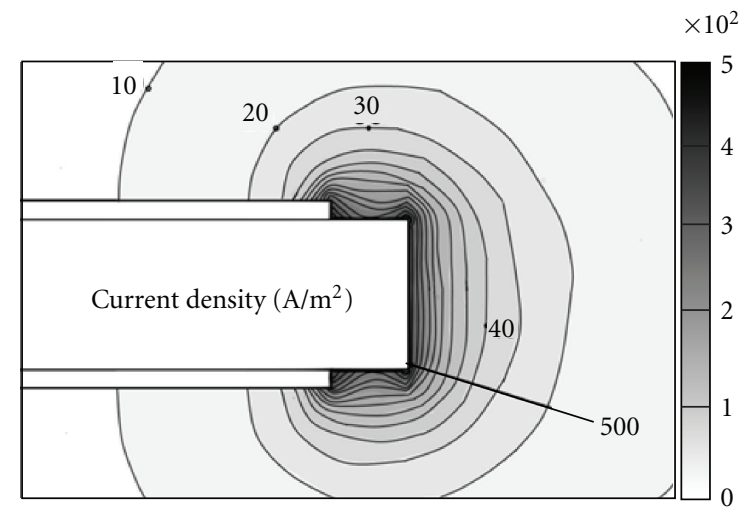

(c)

FIgURE 4: Numerical calculations of (a) the electric potential, (b) the electric field and (c) the current density around a cylindrical unipolar electrode (radius: $100 \mu \mathrm{m}$; see Figure 8) in the STN for an input voltage of $1 \mathrm{~V}$. 
TABLE 1: Dielectric properties of human tissues relevant to numerical simulations of DBS at different frequencies.

\begin{tabular}{lcccccc}
\hline Tissue & \multicolumn{2}{c}{ At $130 \mathrm{~Hz}$} & \multicolumn{2}{c}{ At $1 \mathrm{kHz}$} & \multicolumn{2}{c}{ At $3 \mathrm{kHz}$} \\
& $\begin{array}{c}\text { Conductivity } \\
(\mathrm{S} / \mathrm{m})\end{array}$ & $\begin{array}{c}\text { Relative } \\
\text { permittivity }\end{array}$ & $\begin{array}{c}\text { Conductivity } \\
(\mathrm{S} / \mathrm{m})\end{array}$ & $\begin{array}{c}\text { Relative } \\
\text { permittivity }\end{array}$ & $\begin{array}{c}\text { Conductivity } \\
\text { (S/m) }\end{array}$ & $\begin{array}{c}\text { Relative } \\
\text { permittivity }\end{array}$ \\
\hline Brain gray matter & 0.0915 & 2463000 & 0.0988 & 164060 & 0.10565 & 66831 \\
Brain white matter & 0.0590 & 1069500 & 0.0626 & 69811 & 0.0650 & 30133 \\
Cerebrospinal fluid & 2 & 109 & 2 & 109 & 2 & 109 \\
Dura & 0.5006 & 15276 & 0.5008 & 5344 & 0.5010 & 2360 \\
Skull bone & 0.0201 & 5355 & 0.0202 & 2702 & 0.0203 & 1246 \\
Scalp & 0.0005 & 42909 & 0.0007 & 32135 & 0.0009 & 30569 \\
\hline
\end{tabular}

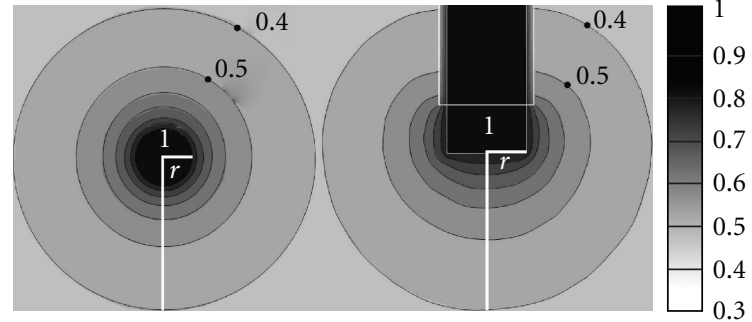

Figure 5: Simulated potential distributions of spherical $(r \sim$ $86.6 \mu \mathrm{m}$, cell constant $\gamma=1.09 \mathrm{~mm})$ and cylindrical $(r=100 \mu \mathrm{m}$, cell constant $\gamma=1.00 \mathrm{~mm}$ ) electrodes.

In contrast, experimental DBS in rat models has often been accompanied by tissue damage, especially during longterm stimulation [56]. This might be the reason why many studies on DBS in rats were restricted to short-term stimulation. However, a recent study showed that tissue damage may also occur during short-term stimulation [57].

These contrasting findings in animals and patients may have various underlying reasons, such as smaller electrode size and blunt edges (higher curvatures), which both result in high field strengths in the vicinity of the electrodes and in higher local current densities leading to more intense local electrode reactions. Electrode reactions and the use of less inert electrode materials, for example, nonnoble metals, result in potentially toxic products, including denatured proteins, gas, dissolved metal ions, and erosion products of the insulating materials. Electrochemical reactions due to energy dissipation at the interface of stimulation electrodes to the surrounding tissue are unavoidable [42]. The degree of tissue damage is determined by the electrode materials. Nonnoble metals, such as stainless steel, may deposit iron ions in the tissue [57]. Metal ions are a potential source of protein-denaturation and the formation of new antigenic determinants leading to immune reactions [58]. Iron is especially known for its cytotoxicity [59]. The degradation of organic compounds and the evolution of gas, such as hydrogen and chlorine, are nonphysiological processes that change the properties of the extracellular fluid. These changes cause neuronal damage [60].

There are a number of parameters that have to be considered when applying electric fields in living tissue. One problem is that no ideally nonpolarizable electrodes, that is, electrodes of the 2nd kind, can be used under experimental or clinical stimulation conditions [42, 51, 61]. Polarizability is the reason for overpotentials. The shape, that is, the amplitudes of the Fourier components of the applied signal, determines the overpotentials that are dissipated in electrode processes (see below). Although electrodes for human use are driven in a constant-voltage mode, constant-current stimulation with square-topped fields is typically used in animal models (Figure 6). In constant-current mode, the electrodes are driven by a voltage function that corrects for energy dissipation by electrode processes [62]. A very important parameter influencing stimulation efficiency is the impedance of the tissue surrounding the electrode. This impedance changes shortly after electrode implantation and over time. An electrically insulating glial sheath forms around the stimulation electrodes in patients $[52,63]$ and in laboratory animals [64]. This sheath is presumably responsible for the increase of electrode impedance after DBS surgery $[65,66]$. Finite element models have identified the thickness and conductivity of the encapsulation layer around the electrode contact and the conductivity of the bulk tissue medium as the main determinants of altered electrode impedance and found an approximately 50\% reduction in the volume of activated tissue using typical DBS settings [67]. However, one study reported a time-dependent decrease of impedance after DBS surgery [68]. Recently, a glial cell culture system has been developed to model the impedance changes after electrode implantation [69]. Because electrode impedance is highly frequency dependent, changes in stimulation parameters that result in a change in the Fourier content may result in changes in stimulation efficiency $[42,61]$.

The rectangular stimulation pulse in Figure 6, as it is used in animals, is comprised of its basic frequency and higher harmonic frequencies, that is, its Fourier content [42]. Thus, if we assume a smooth function for the frequency dependence of the impedance for the harmonic, low amplitude signals, the impedance for every frequency can be calculated from Ohm's law applied to the voltage and current values. Accordingly, it should be possible to calculate the effective electrode impedance from the RMS values of voltage and current for a pulse signal that contains a Fourier spectrum of frequencies. Nevertheless, even for a harmonic signal, the impedance depends on the signal 


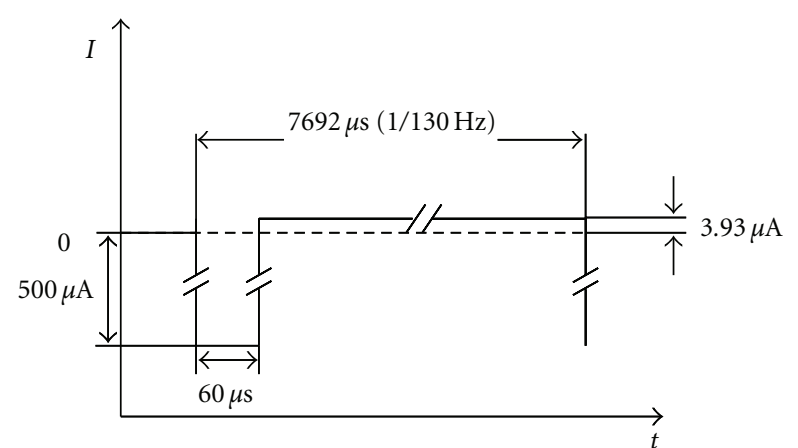

Figure 6: Stimulation pulse as commonly used in the rat model. Please note that the negative stimulation pulse is chargecompensated by the subthreshold positive current between stimulation pulses.

amplitude at every given frequency. Moreover, the chargecarrier transition from electronic currents in the electrode metal to the ionic current in the medium will lead to a nonlinear current voltage relationship and the generation of harmonic frequencies [70]. These complex electrode properties are usually described to include a constant-phase element (CPE; see [42]).

Models to describe this nonlinearity include redox processes requiring a certain activation energy for the chargecarrier transitions and electrochemical reactions, which are summarized under "overpotentials". An additional problem arises from the fact that the nonlinear current transfer function at a given frequency and electrode site (e.g., with a certain curvature) will be influenced by the current induced by the other harmonics or a DC-offset; that is, these currents may contribute to the activation energy required for the charge-carrier transitions at the frequency considered.

In principle, these interrelationships have to be accounted for in models that aim at calculating optimum stimulation parameters that are tailored to the individual patient. Although the situation is not as complicated for the larger electrodes used in humans, which avoid blunt edges and the approach is welladvanced [48], there is too little information on all of the necessary parameters in animal models of DBS where the nonlinear electrode properties play a stronger role (see above).

\section{Effects of Experimental DBS on Neuronal Activity}

Originally, DBS was seen as a functional ablation because of the similarity of its clinical effect to surgical ablation, which suppresses or inhibits the stimulated nucleus. Several neuronal mechanisms of inhibition at the site of and more remote from DBS have been considered. First, direct effects occur as a result of the field application to the neural membrane and result in regions of depolarization and hyperpolarization along each neural process [71, 72]. Therewith, DBS induces alterations in somatic voltage-gated currents that concertedly block neural output at the electrode (depolarization block). In particular, the persistent $\mathrm{Na}^{+}$ current $\left(I_{\mathrm{NaP}}\right)$ is fully blocked, the $\mathrm{Ca}^{2+}$-mediated responses are strongly reduced, suggesting a T- and L-type $\mathrm{Ca}^{2+}$ current depression, whereas the hyperpolarization-activated cationic current $\left(I_{h}\right)$ is not affected [73]. However, DBS may hyperpolarize local neuronal cell bodies and dendrites directly $[37,72]$ or indirectly, given the elevated extracellular $\mathrm{K}+$ levels in experimental Parkinsonism [74], which might interfere with normal activity and generate abnormal activity in neural networks [75]. Second, DBS may elicit indirect effects by activating axon terminals that make synaptic connections with neurons near the stimulating electrode (synaptic inhibition). Experimental and modeling results have shown that afferent inputs have a low threshold for activation during extracellular stimulation [76-80]. Given the large predominance of inhibitory presynaptic terminals in the STN and GPi, their release could locally reduce neuronal activity [81]. Indeed, in vivo [79, 82-86] and in vitro $[73,87-89]$ neural recordings in the stimulated nucleus show decreased activity during and/or after DBS. In contrast, this finding was not confirmed recently by microelectrode recordings in human STN when stimulation was delivered via an actual DBS macroelectrode [90]. Third, on a systemic level, the synaptic transmission of the efferent output of stimulated neurons may fail as a result of transmitter depletion, which results in synaptic depression or functional deafferentiation $[91,92]$.

However, evidence is accumulating for the activation (excitation) of the DBS-stimulated nucleus with subsequent transmission throughout the network. When computer algorithms are used to remove stimulus artifacts, DBS of the STN in primates increases activity in the GPi during stimulation [93]. In turn, this may induce the modulation of pathological activity in the whole network [94]. Recordings from the efferent target nuclei provide the most pertinent neural data on the effects of DBS. In contrast to the above-mentioned studies, in vivo recordings in efferent nuclei indicate that the output of the stimulated nuclei is increased by DBS [95-97]. This is possible despite somatic inhibition because action potential initiation from extracellular stimulation occurs in the axon $[72,98]$. In general, cathodic stimuli generate membrane depolarization in regions near the electrode and membrane hyperpolarization in regions that flank the region of depolarization. The first few nodes of Ranvier are typically depolarized by the stimulus pulse because of the short internodal spacing of the axon compared to the spatial distribution of the field generated by DBS electrodes [37]. There is also early neurophysiological evidence of the occurrence of such phenomena [99-101]. The second effect of extracellular stimulation that supports the decoupling of activity in the axon and cell body during DBS is the activation of transsynaptic inputs in the close surrounding area of the soma (see above). In particular, because DBS-induced action potential initiation occurs in the axon, the efferent output of neurons suprathreshold for direct activation by the applied field is relatively unaffected by the transsynaptic inhibition, and the majority of local cells within $0.2 \mathrm{~mm}$ of the electrode will generate efferent output at the stimulus frequency when the therapeutic stimulation parameters are 
used [37]. This "driven" axonal activity replaces spontaneous intrinsic firing with the exogenously induced patterns [102]. DBS, as an extracellular stimulation, is expected to activate subsets of both afferent and efferent axons, leading to antidromic spikes that collide with the ongoing spontaneous spikes and orthodromic spikes that evoke synaptic responses in target neurons. The cellular basis of this interaction between the anti- and orthodromic spikes is unknown, but this mechanism could converge at the level of the STN axon initial segment where spontaneous firing in STN neurons begins [103]. In addition, neurons subthreshold for direct excitation will exhibit suppression of their intrinsic firing patterns that are regulated by stimulation-induced transsynaptic inputs.

It still is a matter of debate regarding which of the effects of DBS is therapeutically effective and how DBS alleviates motor symptoms. There are at least three viable hypotheses. First, pathological GPi activity is inhibited (see above). Second, STN and GPi DBS induces the regularity of GPi activity [96], thereby reducing misinformation in the pathologically noisy GPi signal and abnormal stochastic resonance [93]. DBS may regularize the pathological synaptic activity of basal ganglia output structures [104] in addition to increasing the firing rate of fibers projecting from the site of stimulation $[37,95,96,105]$. This regularized GPi activity may reduce thalamic error rates (a surrogate for Parkinsonian symptoms) [106] and increase the fidelity of thalamic neurons [107]. This view is experimentally supported by small changes in GPi firing rates in comparison to changes in regularity and bursting activity in response to DBS $[96,104,108]$. Third, DBS activity induces resonance amplification of the information signals in the basal ganglia-thalamus-cortex system necessary for normal movement. Indeed, there are multiple oscillators within this system at many different frequencies, although the main or average frequency is approximately $130 \mathrm{pps}$ [109], and DBS resonates with normal intrinsic oscillators [110]. Basal ganglia oscillations in local field potentials in the 11-30$\mathrm{Hz}$ range are antikinetic $[7,111-113]$; reductions in STN oscillations in this frequency range are correlated with clinical improvement $[114,115]$, and DBS in this frequency range worsens motor performance $[116,117]$. Oscillations in the range of $70 \mathrm{~Hz}$ are thought to be prokinetic because they are lost in Parkinsonism $[7,113,118]$ and restored by levodopa treatment $[116,117]$.

\section{Biochemical and Functional DBS Effects}

Effects of experimental DBS on neuronal activity are also reflected in changes of neurotransmitter release. Microdialysis studies show an increase in striatal dopamine (DA) release, an activation of striatal DA metabolism and an activation of striatal tyrosine hydroxylase (TH) activity [119122]. Furthermore, an enhanced glutamate release in the rat entopeduncular nucleus (EP), the rat analog to the human GPi, during STN stimulation, indicating a facilitated activity of the STN during stimulation $[105,123]$ and an increased GABA release of pallidal origin in the $\mathrm{SNr}$ [124] were demonstrated. These findings are consistent with electrophysiological and theoretical data that suggest an excitation of axons (see Section 4). The described effects may explain the immediate effects of DBS, such as the alleviation of tremor by stimulation of the VIM nucleus of the hypothalamus. However, they cannot readily explain the delayed effects, such as the reduction of rigidity within seconds to a few minutes, the alleviation of hypokinesia after hours or days, the effect of STN DBS on tremor within seconds to days or the effect of GPi DBS on dystonia with a delay of days to weeks. Also, carryover effects can be observed. For example, hypokinesia returns only slowly after the cessation of DBS. These clinical observations suggest that electrical stimuli are translated into network reorganization or effects at the gene expression level.

Gene expression studies indicate that STN DBS may reverse a 6-OHDA lesion-induced increased expression of glutamate decarboxylase-(GAD) $67 \mathrm{mRNA}$ in the EP and in the substantia nigra pars reticulata $(\mathrm{SNr})$ [125]. GAD catalyzes the synthesis of gamma-aminobutyric acid (GABA).

Care should be taken when DBS studies are performed in healthy animals because the data may not equal those acquired in Parkinsonian rats. In a microarray study, mRNAs of synaptic vesicle protein $2 b(S v 2 b)$ and ubiquitinconjugating enzyme E2B are upregulated by DBS in healthy rats but downregulated by DBS in lesioned rats [126]. $\mathrm{Sv} 2 \mathrm{~b}$ is involved in synaptic vesicle exocytosis and thus, neurotransmitter release [127]. E2B plays a role in DNA repair [128] and is required for neurite outgrowth [129]. STN DBS, performed for $2 \mathrm{~h}$ in healthy rats, induced an increase in striatal $\mathrm{TH}$ activity without changes in $\mathrm{TH}$ gene expression determined by a TH activity assay and RT-PCR analysis [122]. In contrast, a microarray analysis combined with real-time PCR and immunohistochemistry showed an upregulation of TH gene expression, but not of THpositive neurons or TH-positive fiber density, by STN DBS in 6-OHDA-lesioned rats [126]. Apparently, DBS effects are altered by an imbalance in the basal ganglia network caused by a 6-OHDA lesion.

We also found a DBS-induced downregulation of calcium/calmodulin-dependent protein kinase-type IIA (CaMKIIa) and Homer1 in 6-OHDA lesioned rats [126]. Both genes are involved in glutamate neurotransmission [130-132]. In addition, we have found an upregulation of insulin-like growth factor 2 (IGF2) and insulin-like growth factor-binding protein 2 (IGFBP2) [126]. As these molecules play a role in postnatal neurogenesis in the hippocampus of mice [133] one could speculate that their upregulation after DBS could indicate a reorganization of the basal ganglia circuitry. An expression of immediate-early genes, for example, $c-f o s$, has been found at the mRNA level [125] with $c$-fos being also induced by L-DOPA treatment in dopamine-denervated marmosets [134] and by immunohistochemistry [135] after STN DBS. The immunohistochemical study demonstrated an upregulation of c-Fos, c-Jun, and Krox-24 not only in the STN but also in the projection areas of the STN [135].

Functional studies, however, require animals that are awake and freely moving. Because of the above-mentioned methodological problems, the latter studies are scarce. 


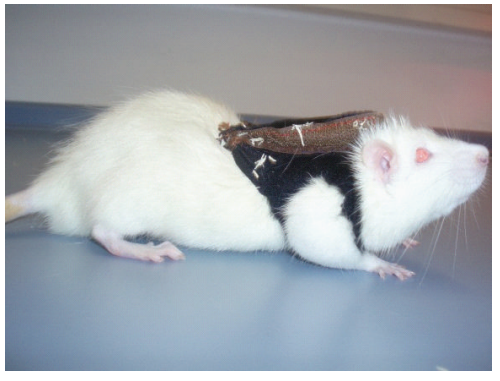

(a)

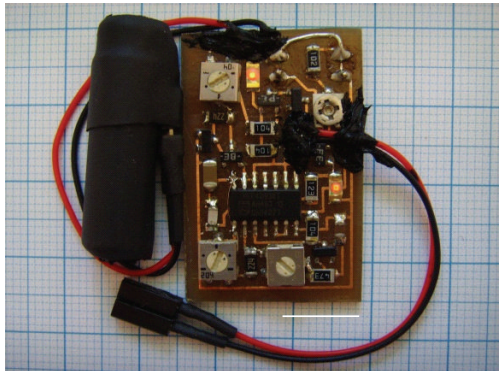

(b)

FIGURE 7: Chronic instrumentation of a freelymoving rat. (a) Rat with a portable stimulator in a backpack; (b) stimulator purchased from the company Rückmann and Arndt, Berlin, Germany. Scale bar in (b): $10 \mathrm{~mm}$.

Darbaky et al. [56] demonstrated an improvement of motor, but not cognitive, functions in 6-OHDA lesioned rats with STN DBS using platinum electrodes connected to a stimulus generator via a swivel. Other studies have found a reversal of limb-use asymmetry and an improvement in treadmill locomotion in 6-OHDA lesioned rats during STN-DBS [136, 137]. The development of instrumentation for freelymoving animals, such as an implantable microstimulation system [64] or a carry-on stimulator (described herein, see Figure 7), promises many more data on functional improvements. Using an implantable microstimulation system, Harnack et al. [138] demonstrated a preservation of dopaminergic nigral neurons in a 6-OHDA rat model with progressive Parkinsonism using chronic STN-DBS.

A role for BDNF is suggested by the results of chronic (14 d) DBS in freely moving 6-OHDA rats, which showed a protection of SNc neurons, arguing for beneficial functional effects of DBS in the early phase of PD [139].

\section{Optimization Strategies for Experimental DBS}

Optimization of DBS aims at (1) achievement of optimum electric coupling without nerve cell damage (2) adjustment to the treatment of different neurological and psychiatric diseases by finding the most effective target and (3) defining optimum stimulation parameters for the specific target. This multivariate testing requires long-term in vivo experiments in the animal model with (a) the systematic investigation of DBS effects under various stimulation conditions; (b) recording of motor and cognitive functions, and (c) analysis of the nervous tissue in the electrode environment on the cellular and molecular level. A prerequisite for such studies is the establishment of a disease model with chronically instrumented freely moving animals. This strategy will facilitate clinical treatment with highest efficacy and the lowest adverse side effects.

6.1. Chronic Instrumentation of Freely Moving Animals. The implementation of an animal model for the research on movement disorders not only requires adequate tests themselves but it also has to allow for the animals to express their natural locomotor behavior to not dismantle their drive for motion and to not change their routines. In the past, external stimulators constrained the animals, because the connecting cables were easily twisted by rotational movements. Also, the large appliances fixed to the animal restricted movements. Thus, such experiments were strongly limited in time. To date, basically three experimental designs allow for longterm experiments. First, housing the rat in an open cage and connecting a cable through the open cage top directly to the animal allows for most movements although it may not solve the rotation problem under all circumstances [139, 140]. Alternatively, animals are housed in cages with open tops allowing the tubes and cables to be connected to a swivel on top [141]. The swivel provides the cables with an additional degree of freedom and can also be set to read the rotation of the animal. A second option, being most promising for long-term animal experiments, is the implantation of the stimulator. This requires a small apparatus with low weight at the expense of a shorter battery life. Stimulation parameters can be adjusted from outside of the animal [64]. As a third option, the animal permanently carries the whole instrumentation in a backpack (Figure 7 ). This allows the device to be significantly larger and better accessible compared to the implantable device. Also, the battery may be exchanged for longer stimulation. In summary, this option combines the advantages of options 1 and 2, because (1) the surgical intervention is much less extensive compared to the implantation of the whole device and (2) the animal can move without constraints. This improved freely moving animal model is suitable for measuring classical druginduced rotation because problems of the restraining cable and tube torsion do not arise.

6.2. Electrode Material and Stimulation Parameters. DBS in rodents requires electrodes that are thinner than those for humans, but it must be stable enough to pierce through the tissue without bending to ensure correct electrode placement. In addition to electrochemical problems arising from these dimensions (see Section 3) stability is an issue limiting the use of platinum/iridium electrodes for testing different electrode tip shapes or multipolar concentric alignments of electrodes. However, corrosion followed by tissue damage occurs when using stainless steel electrodes (see Section 3 ). Keeping in mind that the stimulation parameters can vary 
in many different aspects, such as electrode polarity, current amplitude, and pulse width and frequency, and concerning the standard algorithms that are commonly used for an efficient DBS in humans, we can think about the comparative testing of several simple electrode designs for experimental DBS. One design implies a unipolar cathodic DBS-pulse with a counter electrode underneath the skin for a safe and simple current application just like the common setting used for human therapy with Medtronic devices where the counter electrode is part of the implantable pulse generator (IPG) case. Such an electrode made from platinum/iridium is depicted in Figure 8. Alternative settings consist of bipolar electrodes that can be designed in two different ways:

(1) one concentric bipolar electrode with two concentric contact surfaces, or;

(2) two separate, unipolar electrodes merged together at a region-specific distance.

The unipolar stimulation generates a nearly spherical field distribution, whereas bipolar electrodes produce a more focused field with higher effects in the space between the two electrodes, especially close to the electrode tips and edges. In both cases, the amplitude can be adjusted very precisely in small intervals in analogy to the Medtronic devices. With higher amplitudes, the distributed field increases and can affect structures at a distance from the electrodes, allowing for more neural elements to be stimulated. In the case of DBS of the STN, this may primarily concern the zona incerta and substantia nigra. Newly designed electrodes include sectorial or spot electrodes with a laterally directed field driven in the unipolar or bipolar modes. Such high-perimeter electrodes may increase the variation of current density on the electrode surface, decrease power consumption for the stimulation of axons and reduce the costs and risks of replacement of depleted stimulators [142].

Because of the inverse exponential function describing the interdependence of pulse width and amplitude reflected by the parameters rheobase and chronaxie (see Section 1 for an explanation of these historical items), it is obvious that with higher current amplitudes (i.e., field strength) the pulse width may be lowered nonetheless exciting the surrounding structures of the electrode sufficiently. To protect the treated subject from severe side effects, the stimulation amplitude has to be set as high as needed to reach the most benefit but as low as possible not to exceed the threshold that causes damage by electrochemical reactions and the unintentional excitation of nontarget structures. Chronaxies for DBS effects have been estimated to be around $65 \mu$ s for thalamic and around $75 \mu$ s for pallidal stimulation [143]. In STN DBS, pulse width seems to have minor influence on the improvement of clinical signs. However, higher pulse widths can be used successfully in pallidal stimulation or in the stimulation of thalamic structures, such as the VIM nucleus.

Although the frequencies of a therapeutic effect of DBS are mainly found in a range higher than $100 \mathrm{~Hz}$, this parameter has also to be adjusted for specific areas and pathways. For

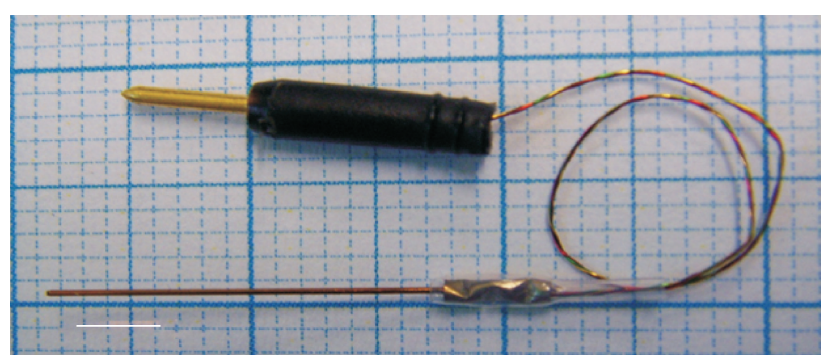

(a)

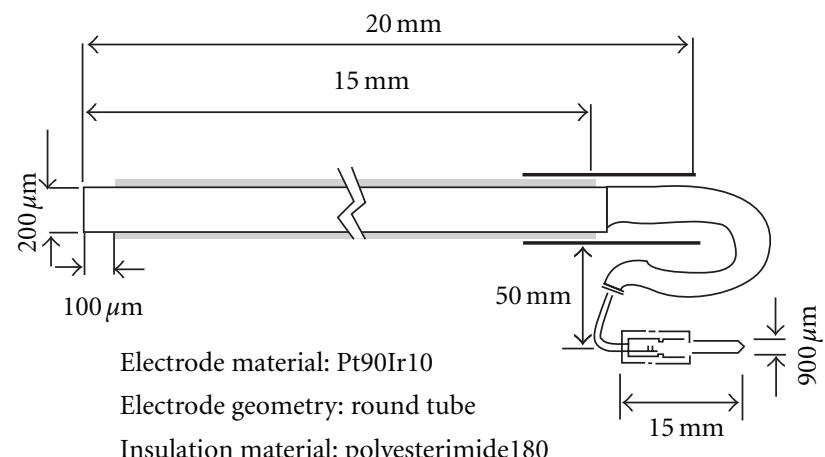

Insulation material: polyesterimide 180

Insulation thickness: $25 \mu \mathrm{m}$

(b)

Figure 8: Photograph (a) and scheme (b) of a custom-made unipolar electrode (POLYFIL, Zug, Switzerland) with the pole made from platinum/iridium (PtIr) for experimental DBS in freely moving chronically instrumented rats. Scale bar in (a): $5 \mathrm{~mm}$.

example, stimulation of the PPN requires a lower stimulation frequency of $20-60 \mathrm{~Hz}$ [144-150]. Because animal models should mimic the clinical situation as closely as possible, we usually apply the human standard of $130 \mathrm{~Hz}$ for STN stimulation in the hemi-Parkinsonian rats as a compromise between power consumption and clinical efficacy, regarding this parameter as being of minor importance for strategies to optimize DBS.

6.3. Closed-Loop Systems. One of the major challenges for future improvements of the DBS technology is the implementation of feedback modulation in so-called closedloop systems involving built-in sensing capabilities. They were first realized for the treatment of epilepsy by taking advantage of EEG recordings for the controlled delivery of DBS to the seizure focus. For this purpose, originally nonimplantable bedside systems have been used, which are meanwhile substituted by implantable automatic devices, such as the responsive neurostimulator (RNS) lead system (NeuroPace, Mountain View, CA, USA) [151-154].

Further progress results from improved stimulation protocols that aim at desynchronizing the pathological oscillations of neuronal activity [155]. They require pulse generators capable of simultaneously recording physiological parameters and providing adapted stimuli. Basically, 
TABLE 2: Experimental DBS with indications and target regions under study.

\begin{tabular}{|c|c|c|}
\hline Indication & Target region & References \\
\hline Parkinson's disease, progressive supranuclear palsy & Pedunculopontine (PPN) nucleus & $\begin{array}{l}{[144-146,} \\
148,149]\end{array}$ \\
\hline $\begin{array}{l}\text { Tremor types other than essential and Parkinsonian } \\
\text { tremor (Holmes tremor, dystonic tremor, thalamic } \\
\text { tremor, essential writer's tremor, and neuropathic } \\
\text { tremor) }\end{array}$ & $\begin{array}{l}\text { Ventrointermediate (VIM), ventral oralis (Vo) and anterior and } \\
\text { posterior nucleus thalami, and subthalamic nucleus (STN) }\end{array}$ & {$[156-159]$} \\
\hline Huntington's disease & Globus pallidusinternus and externus (Gpi and Gpe) & {$[160,161]$} \\
\hline Alzheimer's disease & Fornix/hypothalamus & {$[162]$} \\
\hline Thalamic pain and poststroke fixed dystonia & Posterior limb of internal capsule & {$[163,164]$} \\
\hline $\begin{array}{l}\text { Central nociceptive pain syndromes (ischemia, } \\
\text { hemorrhage, multiple sclerosis, spinal cord, and injury) }\end{array}$ & Periaqueductal/periventricular gray matter (PAG/PVG) & {$[165]$} \\
\hline $\begin{array}{l}\text { Peripheral neuropathic pain (postzoster neuralgia, } \\
\text { radiogenic plexus lesion, phantom pain, } \\
\text { postdissectomy syndrome, chronic radiculopathy, and } \\
\text { carcinoma pain) }\end{array}$ & $\begin{array}{l}\text { Ventroposterolateral/ventroposteromedial (VPL/VPM) nucleus } \\
\text { thalami, ventrocaudal }(\mathrm{Vc}) \text { nucleus thalami, medial lemniscus, } \\
\text { and PAG/PVG }\end{array}$ & {$[165,166]$} \\
\hline Epilepsy & $\begin{array}{l}\text { Anterior and centromedian nucleus (AN and CMN) thalami, } \\
\text { mammillary body }(\mathrm{MB}) \text { hypothalamic and mamillothalamic tract, } \\
\text { STN, hippocampus, caudate nucleus }(\mathrm{CN}) \text {, and cerebellum }\end{array}$ & {$[167,168]$} \\
\hline Obsessive-compulsive disorder & $\begin{array}{l}\text { Anterior limb of internal capsule (ALIC), STN, ventral caudate, } \\
\text { inferior thalamic peduncle, nucleus accumbens (NAc), and ventral } \\
\text { capsule/ventral striatum (VC/VS) }\end{array}$ & $\begin{array}{l}{[25-} \\
29,169- \\
171]\end{array}$ \\
\hline Depression & $\begin{array}{l}\text { Subcallosal cingulated gyrus, inferior thalamic peduncle, NAc, } \\
\text { VC/VS }\end{array}$ & $\begin{array}{c}{[29,172-} \\
174]\end{array}$ \\
\hline Gilles de la Tourette syndrome & $\begin{array}{l}\text { Centromedian-parafascicular (Cm-Pf) and Vo complex thalami, } \\
\text { Gpi, and NAc }\end{array}$ & {$[17,29]$} \\
\hline Minimally conscious state & Central thalamus & {$[175]$} \\
\hline
\end{tabular}

three different methods of desynchronizing stimulation with putative therapeutic impact have been developed:

(1) coordinated reset stimulation,

(2) nonlinear delayed feedback stimulation,

(3) multisite coordinated delayed feedback stimulation [155].

These methods will ultimately contribute to the optimization of the DBS technology in the clinical practice too.

6.4. Novel Target Regions and Indications. The expanding spectrum of neuropsychiatric diseases tested for the putative therapeutic effects of DBS requires a high flexibility of stimulation parameters. Efforts are also directed toward the search for suitable target regions. Nevertheless, most of these efforts follow a trial-and-error strategy. Of special interest, clinical problems of cognitive impairment and late-stage PD may be alleviated by DBS with modified frequencies and the targeting of the PPN. For example, impaired working memory is improved by the low-frequency $(25 \mathrm{~Hz})$ stimulation of the PPN [176]. In severe cases of late-stage PD with postural instability and freezing of gait, dual stimulation of the PPN with $25 \mathrm{~Hz}$ and of the STN with $60 \mathrm{~Hz}$ reveals a higher synergistic effect compared to STN-DBS or PPN-DBS alone [177]. The PPN is also targeted to reduce falls [148] and reaction times during motor tasks in PD [149]. Chronic low-frequency stimulation $(25 \mathrm{~Hz})$ of the PPN has been shown to restore functional connectivity [150]. Interestingly, a modification of DBS, using the dorsal column of the spinal cord as the target, enables functional recovery in chronic bilaterally 6-OHDA-lesioned PD rats [178, 179]. However, this could not be confirmed in initial clinical studies on PD patients [180]. Application of DBS in the centrum medianum-parafascicularis(Cm-Pf) complex for patients in a vegetative state is controversial as patients respond poorly if at all $[181,182]$. A survey of potential candidates for DBS beyond movement disorders that are already approved for clinical DBS, such as PD (see Section 1.2), is given in Table 2. Notably, the survey by no means claims completeness. However, future studies will probably reduce the number of appropriate target regions of DBS for diverse indications. Therefore, an optimization concerning appropriate targets for any indication will be achieved.

6.5. Transgenic Disease Models. Drawbacks of the toxic animal models described in Section 1.3 are differences in the genetic background (healthy animals versus genetically susceptible patients) and in the pathogenetic mechanisms, whereby the models only partly mirror the pathogenesis and therapeutic response of the human diseases. In this situation, the transgenic technology has several advantages. 
It provides a potentially unlimited number of animals that either lack or overexpress genes that have been identified as pathogenetically relevant risk genes in humans. For example, by introducing mutated candidate genes, transgenic models have been generated for the following:

(1) PD with $\alpha$-synuclein (PARK1 gene) [183],

(2) Huntington's disease with huntingtin (HTT gene) [184],

(3) dystonia with torsinA (DYT1 gene) [185].

Of advantage is also the possibility for the exploration of certain details of the mechanisms of action of DBS using gene-targeted animals. For example, adenosine A1 receptormutant mice (knockout or null mice) have contributed to the elucidation of the role of adenosine for the suppression of essential tremor by DBS [24].

\section{Conclusions and Outlook}

Despite new and promising developments in the field of transgenic animal technology, the conventional 6-OHDA hemi-PD rat model is still suitable for the investigation of various aspects of experimental DBS, such as the analysis of electrochemical processes at the electrode/tissue interface and of molecular and cellular changes in the tissue surrounding the stimulating electrode. For optimization, new electrode materials and modified surface structures are investigated in combination with computational simulation and numerical electric field calculations. Also, new target regions are tested for effects of DBS on motor and cognitive functions assessed by specific behavioral tests. The final aim is the improvement of the efficacy and safety of DBS in clinical practice. Future investigations will concern the following issues, among others:

(1) optimization of pulse shape (f-content) to reduce adverse effects (such as electrode reactions and cell damage) to the system,

(2) technical improvements with smaller, rechargeable and sensor-containing DBS devices that enable current steering and closed-loop stimulation [154],

(3) desynchronization of pathological oscillatory excitations [155],

(4) a combination of fiber optic and optogenetic technology for the stimulation of selected neuronal populations [186],

(5) transgenic and primate animal models of movement disorders for the further elucidation of the mechanisms of action of DBS and for the more precise targeting of specific cell types by DBS [187],

(6) an individualized combination of therapies of DBS and medication,

(7) innovations such as microstimulation via brainmachine interfaces [188] and electrical microarray implants (NeuroNexus Technologies, Ann Arbor, MI, USA), which are being tested in animal models of human diseases.
These investigations will not only allow for a deeper insight into DBS mechanisms but also provide significant therapeutic benefit for patients with neuropsychiatric diseases, in particular in movement disorders such as PD [18].

\section{Acknowledgments}

This study was supported by the German research foundation (DFG-Graduiertenkolleg 1505/1). K. K. Sriperumbudur was financed by a Grant from the Federal Ministry for Education and Research (BMBF; FKZ 01EZ0911). M. Stubbe is acknowledged for help with COMSOL calculations. The authors are indebted to Dr. R. Arndt (Humboldt University, Berlin, Germany) for constructing the portable stimulator. The company POLYFIL AG (Zug, Switzerland) is acknowledged for providing custom-made stimulation electrodes.

\section{References}

[1] E. A. Spiegel, H. T. Wycis, M. Marks, and A. J. Lee, "Stereotaxic apparatus for operations on the human brain," Science, vol. 106, no. 2754, pp. 349-350, 1947.

[2] R. Hassler, T. Riechert, F. Mundinger, W. Umbach, and J. A. Ganglberger, "Physiological observations in stereotaxic operations in extrapyramidal motor disturbances," Brain, vol. 83, no. 2, pp. 337-350, 1960.

[3] N. P. Bechtereva, A. N. Bondartchuk, V. M. Smirnov, and L. A. Melyucheva, "Therapeutic electric stimulation of deeplying brain structures," Zhurnal Voprosy Neirokhirurgii, vol. 1, pp. 7-12, 1972.

[4] F. Mundinger, "New stereotactic treatment of spasmodic torticollis with a brain stimulation system," Medizinische Klinik, vol. 72, no. 46, pp. 1982-1986, 1977.

[5] J. Siegfried and B. Lippitz, "Chronic electric stimulation of the VL-VPL complex and of the pallidum in the treatment of movement disorders: personal experience since 1982," Stereotactic and Functional Neurosurgery, vol. 62, no. 1-4, pp. 71-75, 1994.

[6] A. L. Benabid, P. Pollak, A. Louveau, S. Henry, and J. De Rougemont, "Combined (thalamotomy and stimulation) stereotactic surgery of the VIM thalamic nucleus for bilateral Parkinson disease," Applied Neurophysiology, vol. 50, no. 1-6, pp. 344-346, 1987.

[7] M. L. Kringelbach, A. L. Green, S. L. F. Owen, P. M. Schweder, and T. Z. Aziz, "Sing the mind electric_principles of deep brain stimulation," European Journal of Neuroscience, vol. 32, no. 7, pp. 1070-1079, 2010.

[8] W. Irnich, "The terms "chronaxie" and "rheobase" are 100 years old," Pacing and Clinical Electrophysiology, vol. 33, no. 4, pp. 491-496, 2010.

[9] J. Voges, "Deep brain stimulation for the treatment of movement disorders," Journal of Korean Neurosurgical Society, vol. 34, pp. 281-298, 2003.

[10] A. R. Rezai, A. G. Machado, M. Deogaonkar, H. Azmi, C. Kubu, and N. M. Boulis, "Surgery for movement disorders," Neurosurgery, vol. 62, no. 2, pp. 809-838, 2008.

[11] A. Lozano, P. L. Gildenberg, and R. R. Tasker, Textbook of Stereotactic and Functional Neurosurgery, Springer, New York, NY, USA, 2009.

[12] W. J. Elias and A. M. Lozano, "Deep brain stimulation: the spectrum of application," Neurosurgical Focus, vol. 29, no. 2, 2010 . 
[13] M. I. Hariz, P. Blomstedt, and L. Zrinzo, "Deep brain stimulation between 1947 and 1987: the untold story," Neurosurgical Focus, vol. 29, no. 2, article E1, 10 pages, 2010.

[14] A. L. Benabid, P. Pollak, C. Gervason et al., "Long-term suppression of tremor by chronic stimulation of the ventral intermediate thalamic nucleus," Lancet, vol. 337, no. 8738, pp. 403-406, 1991.

[15] G. Deuschl, C. Schade-Brittinger, P. Krack et al., "A randomized trial of deep-brain stimulation for Parkinson's disease," New England Journal of Medicine, vol. 355, no. 9, pp. 896-908, 2006.

[16] A. Kupsch, R. Benecke, J. Müller et al., "Pallidal deep-brain stimulation in primary generalized or segmental dystonia," New England Journal of Medicine, vol. 355, no. 19, pp. 19781990, 2006.

[17] M. I. Hariz and M. M. Robertson, "Gilles de la Tourette syndrome and deep brain stimulation," European Journal of Neuroscience, vol. 32, no. 7, pp. 1128-1134, 2010.

[18] P. Gubellini, P. Salin, L. Kerkerian-Le Goff, and C. Baunez, "Deep brain stimulation in neurological diseases and experimental models: from molecule to complex behavior," Progress in Neurobiology, vol. 89, no. 1, pp. 79-123, 2009.

[19] U. Ungerstedt, "6-hydroxy-dopamine induced degeneration of central monoamine neurons," European Journal of Pharmacology, vol. 5, no. 1, pp. 107-110, 1968.

[20] K. S. Bankiewicz, E. H. Oldfield, C. C. Chiueh, J. L. Doppman, D. M. Jacobowitz, and I. J. Kopin, "Hemiparkinsonism in monkeys after unilateral internal carotid artery infusion of 1-methyl-4-phenyl-1,2,3,6-tetrahydropyridine (MPTP)," Life Sciences, vol. 39, no. 1, pp. 7-16, 1986.

[21] R. E. Heikkila, A. Hess, and R. C. Duvoisin, "Dopaminergic neurotoxicity of 1-methyl-4-phenyl1,2,5,6-tetrahydropyridine in mice," Science, vol. 224, no. 4656, pp. 1451-1453, 1984.

[22] R. S. Burns, C. C. Chiueh, and S. P. Markey, "A primate model of parkinsonism: selective destruction of dopaminergic neurons in the pars compacta of the substantia nigra by N-methyl-4-phenyl-1,2,3,6-tetrahydropyridine," Proceedings of the National Academy of Sciences of the United States of America, vol. 80, no. 14, pp. 4546-4550, 1983.

[23] F. C. Martin, A. T. Le, and A. Handforth, "Harmalineinduced tremor as a potential preclinical screening method for essential tremor medications," Movement Disorders, vol. 20, no. 3, pp. 298-305, 2005.

[24] L. Bekar, W. Libionka, G. F. Tian et al., "Adenosine is crucial for deep brain stimulation-mediated attenuation of tremor," Nature Medicine, vol. 14, no. 1, pp. 75-80, 2008.

[25] A. Mundt, J. Klein, D. Joel et al., "High-frequency stimulation of the nucleus accumbens core and shell reduces quinpiroleinduced compulsive checking in rats," European Journal of Neuroscience, vol. 29, no. 12, pp. 2401-2412, 2009.

[26] O. Klavir, S. Flash, C. Winter, and D. Joel, "High frequency stimulation and pharmacological inactivation of the subthalamic nucleus reduces 'compulsive' lever-pressing in rats," Experimental Neurology, vol. 215, no. 1, pp. 101-109, 2009.

[27] O. Klavir, C. Winter, and D. Joel, "High but not low frequency stimulation of both the globus pallidus and the entopeduncular nucleus reduces 'compulsive' lever-pressing in rats," Behavioural Brain Research, vol. 216, no. 1, pp. 8493, 2011.

[28] M. K. Mian, M. Campos, S. A. Sheth, and E. N. Eskandar, "Deep brain stimulation for obsessive-compulsive disorder: past, present, and future," Neurosurgical Focus, vol. 29, no. 2, p. E10, 2010.
[29] H. E. Ward, N. Hwynn, and M. S. Okun, "Update on deep brain stimulation for neuropsychiatric disorders," Neurobiology of Disease, vol. 38, no. 3, pp. 346-353, 2010.

[30] G. A. Metz, A. Tse, M. Ballermann, L. K. Smith, and K. Fouad, "The unilateral 6-OHDA rat model of Parkinson's disease revisited: an electromyographic and behavioural analysis," European Journal of Neuroscience, vol. 22, no. 3, pp. 735-744, 2005.

[31] M. A. Cenci, I. Q. Whishaw, and T. Schallert, "Animal models of neurological deficits: how relevant is the rat?" Nature Reviews Neuroscience, vol. 3, no. 7, pp. 574-579, 2002.

[32] A. Klein, J. Wessolleck, A. Papazoglou, G. A. Metz, and G. Nikkhah, "Walking pattern analysis after unilateral 6-OHDA lesion and transplantation of foetal dopaminergic progenitor cells in rats," Behavioural Brain Research, vol. 199, no. 2, pp. 317-325, 2009.

[33] R. J. Mandel, P. Brundin, and A. Bjorklund, "The importance of graft placement and task complexity for transplantinduced recovery of simple and complex sensorimotor deficits in dopamine denervated rats," European Journal of Neuroscience, vol. 2, no. 10, pp. 888-894, 1990.

[34] M. LeDoux, Animal Models of Movement Disorders, Elsevier Academic Press, Burlington, Vt, USA, 2005.

[35] J. B. Ranck Jr., "Which elements are excited in electrical stimulation of mammalian central nervous system: a review," Brain Research, vol. 98, no. 3, pp. 417-440, 1975.

[36] A. G. Richardson, C. C. McIntyre, and W. M. Grill, "Modelling the effects of electric fields on nerve fibres: influence of the myelin sheath," Medical and Biological Engineering and Computing, vol. 38, no. 4, pp. 438-446, 2000.

[37] C. C. McIntyre, W. M. Grill, D. L. Sherman, and N. V. Thakor, "Cellular effects of deep brain stimulation: modelbased analysis of activation and inhibition," Journal of Neurophysiology, vol. 91, no. 4, pp. 1457-1469, 2004.

[38] F. Rattay, S. Resatz, P. Lutter, K. Minassian, B. Jilge, and M. R. Dimitrijevic, "Mechanisms of electrical stimulation with neural prostheses," Neuromodulation, vol. 6, no. 1, pp. 42-56, 2003.

[39] U. Gimsa, U. Schreiber, B. Habel, J. Flehr, U. Van Rienen, and J. Gimsa, "Matching geometry and stimulation parameters of electrodes for deep brain stimulation experimentsnumerical considerations," Journal of Neuroscience Methods, vol. 150, no. 2, pp. 212-227, 2006.

[40] W. M. Grill, "Modeling the effects of electric fields on nerve fibers: influence of tissue electrical properties," IEEE Transactions on Biomedical Engineering, vol. 46, no. 8, pp. 918-928, 1999.

[41] C. H. Wolters, A. Anwander, X. Tricoche, D. Weinstein, M. A. Koch, and R. S. MacLeod, "Influence of tissue conductivity anisotropy on EEG/MEG field and return current computation in a realistic head model: a simulation and visualization study using high-resolution finite element modeling," NeuroImage, vol. 30, no. 3, pp. 813-826, 2006.

[42] J. Gimsa, B. Habel, U. Schreiber, U. V. Rienen, U. Strauss, and U. Gimsa, "Choosing electrodes for deep brain stimulation experiments-electrochemical considerations," Journal of Neuroscience Methods, vol. 142, no. 2, pp. 251-265, 2005.

[43] T. R. Gowrishankar and J. C. Weaver, "An approach to electrical modeling of single and multiple cells," Proceedings of the National Academy of Sciences of the United States of America, vol. 100, no. 6, pp. 3203-3208, 2003.

[44] J. Gimsa and D. Wachner, "On the analytical description of transmembrane voltage induced on spheroidal cells with zero membrane conductance," European Biophysics Journal, vol. 30, no. 6, pp. 463-466, 2001. 
[45] J. Gimsa and D. Wachner, "Analytical description of the transmembrane voltage induced on arbitrarily oriented ellipsoidal and cylindrical cells," Biophysical Journal, vol. 81, no. 4, pp. 1888-1896, 2001.

[46] C. R. Butson and C. C. McIntyre, "Role of electrode design on the volume of tissue activated during deep brain stimulation," Journal of Neural Engineering, vol. 3, no. 1, pp. $1-8,2006$.

[47] S. Miocinovic, S. F. Lempka, G. S. Russo et al., "Experimental and theoretical characterization of the voltage distribution generated by deep brain stimulation," Experimental Neurology, vol. 216, no. 1, pp. 166-176, 2009.

[48] A. Chaturvedi, C. R. Butson, S. F. Lempka, S. E. Cooper, and C. C. McIntyre, "Patient-specific models of deep brain stimulation: influence of field model complexity on neural activation predictions," Brain Stimulation, vol. 3, pp. 65-67, 2010.

[49] M. Faraday, Experimental Researches in Chemistry and Physics, 1859.

[50] K. J. Vetter, Elektrochemische Kinetik, Springer, Berlin, Germany, 1961.

[51] P. W. Atkins, Physical Chemistry, Oxford University Press, Oxford, UK, 1991.

[52] C. Haberler, F. Alesch, P. R. Mazal et al., "No tissue damage by chronic deep brain stimulation in Parkinson's disease," Annals of Neurology, vol. 48, no. 3, pp. 372-376, 2000.

[53] J. M. Henderson, M. Pell, D. J. O’Sullivan et al., "Postmortem analysis of bilateral subthalamic electrode implants in Parkinson's disease," Movement Disorders, vol. 17, no. 1, pp. 133-137, 2002.

[54] J. Moss, T. Ryder, T. Z. Aziz, M. B. Graeber, and P. G. Bain, "Electron microscopy of tissue adherent to explanted electrodes in dystonia and Parkinson's disease," Brain, vol. 127, no. 12, pp. 2755-2763, 2004.

[55] K. Van Kuyck, M. Welkenhuysen, L. Arckens, R. Sciot, and B. Nuttin, "Histological alterations induced by electrode implantation and electrical stimulation in the human brain: a review," Neuromodulation, vol. 10, no. 3, pp. 244-261, 2007.

[56] Y. Darbaky, C. Forni, M. Amalric, and C. Baunez, "High frequency stimulation of the subthalamic nucleus has beneficial antiparkinsonian effects on motor functions in rats, but less efficiency in a choice reaction time task," European Journal of Neuroscience, vol. 18, no. 4, pp. 951-956, 2003.

[57] D. Harnack, C. Winter, W. Meissner, T. Reum, A. Kupsch, and R. Morgenstern, "The effects of electrode material, charge density and stimulation duration on the safety of highfrequency stimulation of the subthalamic nucleus in rats," Journal of Neuroscience Methods, vol. 138, no. 1-2, pp. 207216, 2004.

[58] H. Zitter and H. Plenk, "The electrochemical behavior of metallic implant materials as an indicator of their biocompatibility," Journal of Biomedical Materials Research, vol. 21, no. 7, pp. 881-896, 1987.

[59] J. Smythies, "The neurotoxicity of glutamate, dopamine, iron and reactive oxygen species: functional interrelationships in health and disease: a review-discussion," Neurotoxicity Research, vol. 1, pp. 27-39, 1999.

[60] M. M. Iravani, S. Costa, M. J. Jackson et al., "GDNF reverses priming for dyskinesia in MPTP-treated, L-DOPA-primed common marmosets," European Journal of Neuroscience, vol. 13, no. 3, pp. 597-608, 2001.

[61] X. F. Wei and W. M. Grill, "Impedance characteristics of deep brain stimulation electrodes in vitro and in vivo," Journal of Neural Engineering, vol. 6, no. 4, Article ID 046008, 2009.
[62] J. Gimsa, B. Habel, U. Schreiber, U. V. Rienen, U. Strauss, and U. Gimsa, "Choosing electrodes for deep brain stimulation experiments-electrochemical considerations," Journal of Neuroscience Methods, vol. 142, no. 2, pp. 251-265, 2005.

[63] M. S. Nielsen, C. R. Bjarkam, J. C. Sørensen, M. BojsenMøller, N. AA. Sunde, and K. Østergaard, "Chronic subthalamic high-frequency deep brain stimulation in Parkinson's disease-a histopathological study," European Journal of Neurology, vol. 14, no. 2, pp. 132-138, 2007.

[64] D. Harnack, W. Meissner, R. Paulat et al., "Continuous highfrequency stimulation in freely moving rats: development of an implantable microstimulation system," Journal of Neuroscience Methods, vol. 167, no. 2, pp. 278-291, 2008.

[65] S. F. Lempka, S. Miocinovic, M. D. Johnson, J. L. Vitek, and C. C. McIntyre, "In vivo impedance spectroscopy of deep brain stimulation electrodes," Journal of Neural Engineering, vol. 6, no. 4, Article ID 046001, 2009.

[66] S. F. Lempka, M. D. Johnson, S. Miocinovic, J. L. Vitek, and C. C. McIntyre, "Current-controlled deep brain stimulation reduces in vivo voltage fluctuations observed during voltagecontrolled stimulation," Clinical Neurophysiology, vol. 121, pp. 2128-2133, 2010.

[67] C. R. Butson, C. B. Maks, and C. C. McIntyre, "Sources and effects of electrode impedance during deep brain stimulation," Clinical Neurophysiology, vol. 117, no. 2, pp. 447-454, 2006.

[68] M. Rosa, S. Marceglia, D. Servello et al., "Time dependent subthalamic local field potential changes after DBS surgery in Parkinson's disease," Experimental Neurology, vol. 222, no. 2, pp. 184-190, 2010.

[69] J. P. Frampton, M. R. Hynd, M. L. Shuler, and W. Shain, "Effects of glial cells on electrode impedance recorded from neural prosthetic devices in vitro," Annals of Biomedical Engineering, vol. 38, no. 3, pp. 1031-1047, 2010.

[70] H. P. Schwan and B. Onaral, "Linear and nonlinear properties of platinum electrode polarisation III: equivalence of frequency- and time-domain behaviour," Medical and Biological Engineering and Computing, vol. 23, no. 1, pp. 2832, 1985.

[71] F. Rattay, "High frequency electrostimulation of excitable cells," Journal of Theoretical Biology, vol. 123, no. 1, pp. 4554, 1986.

[72] C. C. McIntyre and W. M. Grill, "Excitation of central nervous system neurons by nonuniform electric fields," Biophysical Journal, vol. 76, no. 2, pp. 878-888, 1999.

[73] C. Beurrier, B. Bioulac, J. Audin, and C. Hammond, "Highfrequency stimulation produces a transient blockade of voltage-gated currents in subthalamic neurons," Journal of Neurophysiology, vol. 85, no. 4, pp. 1351-1356, 2001.

[74] U. Strauss, F. W. Zhou, J. Henning et al., "Increasing extracellular potassium results in subthalamic neuron activity resembling that seen in a 6-hydroxydopamine lesion," Journal of Neurophysiology, vol. 99, no. 6, pp. 2902-2915, 2008.

[75] D. M. Durand, E.-H. Park, and A. L. Jensen, "Potassium diffusive coupling in neural networks," Philosophical Transactions of the Royal Society B, vol. 365, no. 1551, pp. 2347-2362, 2010.

[76] F. Baldissera, A. Lundberg, and M. Udo, "Activity evoked from the mesencephalic tegmentum in descending pathways other than the rubrospinal tract," Experimental Brain Research, vol. 15, no. 2, pp. 133-150, 1972.

[77] E. Jankowska, Y. Padel, and R. Tanaka, "The mode of activation of pyramidal tract cells by intracortical stimuli," Journal of Physiology, vol. 249, no. 3, pp. 617-636, 1975. 
[78] B. Gustafsson and E. Jankowska, "Direct and indirect activation of nerve cells by electrical pulses applied extracellularly," Journal of Physiology, vol. 258, no. 1, pp. 33-61, 1976.

[79] J. O. Dostrovsky, R. Levy, J. P. Wu, W. D. Hutchison, R. R. Tasker, and A. M. Lozano, "Microstimulation-induced inhibition of neuronal firing in human globus pallidus," Journal of Neurophysiology, vol. 84, no. 1, pp. 570-574, 2000.

[80] C. C. McIntyre and W. M. Grill, "Extracellular stimulation of central neurons: influence of stimulus waveform and frequency on neuronal output," Journal of Neurophysiology, vol. 88, no. 4, pp. 1592-1604, 2002.

[81] K. H. Lee, S. Y. Chang, D. W. Roberts, and U. Kim, "Neurotransmitter release from high-frequency stimulation of the subthalamic nucleus," Journal of Neurosurgery, vol. 101, no. 3, pp. 511-517, 2004.

[82] A. Benazzouz, B. Piallat, P. Pollak, and A. L. Benabid, "Responses of substantia nigra pars reticulata and globus pallidus complex to high frequency stimulation of the subthalamic nucleus in rats: electrophysiological data," Neuroscience Letters, vol. 189, no. 2, pp. 77-80, 1995.

[83] A. Benazzouz, D. Gao, Z. Ni, and A. L. Benabid, "High frequency stimulation of the STN influences the activity of dopamine neurons in the rat," NeuroReport, vol. 11, no. 7, pp. 1593-1596, 2000.

[84] T. Boraud, E. Bezard, B. Bioulac, and C. Gross, "High frequency stimulation of the internal Globus Pallidus (GPi) simultaneously improves parkinsonian symptoms and reduces the firing frequency of GPi neurons in the MPTPtreated monkey," Neuroscience Letters, vol. 215, no. 1, pp. 1720, 1996.

[85] Y. R. Wu, R. Levy, P. Ashby, R. R. Tasker, and J. O. Dostrovsky, "Does stimulation of the GPi control dyskinesia by activating inhibitory axons?" Movement Disorders, vol. 16, no. 2, pp. 208-216, 2001.

[86] C. H. Tai, T. Boraud, E. Bezard, B. Bioulac, C. Gross, and A. Benazzouz, "Electrophysiological and metabolic evidence that high-frequency stimulation of the subthalamic nucleus bridles neuronal activity in the subthalamic nucleus and the substantia nigra reticulata," FASEB Journal, vol. 17, no. 13, pp. 1820-1830, 2003.

[87] Z. H. T. Kiss, D. M. Mooney, L. Renaud, and B. Hu, "Neuronal response to local electrical stimulation in rat thalamus: physiological implications for mechanisms of deep brain stimulation," Neuroscience, vol. 113, no. 1, pp. 137-143, 2002.

[88] C. Magarios-Ascone, J. H. Pazo, O. Macadar, and W. Buo, "High-frequency stimulation of the subthalamic nucleus silences subthalamic neurons: a possible cellular mechanism in Parkinson's disease," Neuroscience, vol. 115, no. 4, pp. 1109-1117, 2002.

[89] L. Garcia, J. Audin, G. D’Alessandro, B. Bioulac, and C. Hammond, "Dual effect of high-frequency stimulation on subthalamic neuron activity," Journal of Neuroscience, vol. 23, no. 25, pp. 8743-8751, 2003.

[90] J. D. Carlson, D. R. Cleary, J. S. Cetas, M. M. Heinricher, and K. J. Burchiel, "Deep brain stimulation does not silence neurons in subthalamic nucleus in Parkinson's patients," Journal of Neurophysiology, vol. 103, no. 2, pp. 962-967, 2010.

[91] F. J. Urbano, E. Leznik, and R. R. Llinás, "Cortical activation patterns evoked by afferent axons stimuli at different frequencies: an in vitro voltage-sensitive dye imaging study," Thalamus and Related Systems, vol. 1, no. 4, pp. 371-378, 2002.
[92] K. J. Iremonger, T. R. Anderson, B. Hu, and Z. H. T. Kiss, "Cellular mechanisms preventing sustained activation of cortex during subcortical high-frequency stimulation," Journal of Neurophysiology, vol. 96, no. 2, pp. 613-621, 2006.

[93] E. B. Montgomery Jr. and J. T. Gale, "Mechanisms of action of deep brain stimulation (DBS)," Neuroscience and Biobehavioral Reviews, vol. 32, no. 3, pp. 388-407, 2008.

[94] E. B. Montgomery Jr. and K. B. Baker, "Mechanisms of deep brain stimulation and future technical developments," Neurological Research, vol. 22, no. 3, pp. 259-266, 2000.

[95] M. E. Anderson, N. Postupna, and M. Ruffo, "Effects of highfrequency stimulation in the internal globus pallidus on the activity of thalamic neurons in the awake monkey," Journal of Neurophysiology, vol. 89, no. 2, pp. 1150-1160, 2003.

[96] T. Hashimoto, C. M. Elder, M. S. Okun, S. K. Patrick, and J. L. Vitek, "Stimulation of the subthalamic nucleus changes the firing pattern of pallidal neurons," Journal of Neuroscience, vol. 23, no. 5, pp. 1916-1923, 2003.

[97] N. Maurice, A. M. Thierry, J. Glowinski, and J. M. Deniau, "Spontaneous and evoked activity of substantia nigra pars reticulata neurons during high-frequency stimulation of the subthalamic nucleus," Journal of Neuroscience, vol. 23, no. 30, pp. 9929-9936, 2003.

[98] L. G. Nowak and J. Bullier, "Axons, but not cell bodies, are activated by electrical stimulation in cortical gray matter. II. Evidence from selective inactivation of cell bodies and axon initial segments," Experimental Brain Research, vol. 118, no. 4, pp. 489-500, 1998.

[99] J. S. Coombs, D. R. Curtis, and J. C. Eccles, "The interpretation of spike potentials of motoneurones," The Journal of Physiology, vol. 139, no. 2, pp. 198-231, 1957.

[100] R. Llinas and C. A. Terzuolo, "Mechanisms of supraspinal actions upon spinal cord activities. Reticular inhibitory mechanisms on alpha-extensor motoneurons," Journal of Neurophysiology, vol. 27, pp. 579-591, 1964.

[101] M. Steriade, M. Deschenes, and G. Oakson, "Inhibitory processes and interneuronal apparatus in motor cortex during sleep and waking. I. Background firing and responsiveness of pyramidal tract neurons and interneurons," Journal of Neurophysiology, vol. 37, no. 5, pp. 1065-1092, 1974.

[102] C. Hammond, R. Ammari, B. Bioulac, and L. Garcia, "Latest view on the mechanism of action of deep brain stimulation," Movement Disorders, vol. 23, no. 15, pp. 2111-2121, 2008.

[103] J. F. Atherton, D. L. Wokosin, S. Ramanathan, and M. D. Bevan, "Autonomous initiation and propagation of action potentials in neurons of the subthalamic nucleus," Journal of Physiology, vol. 586, no. 23, pp. 5679-5700, 2008.

[104] W. Meissner, A. Leblois, D. Hansel et al., "Subthalamic high frequency stimulation resets subthalamic firing and reduces abnormal oscillations," Brain, vol. 128, no. 10, pp. 23722382, 2005.

[105] F. Windels, N. Bruet, A. Poupard, C. Feuerstein, A. Bertrand, and M. Savasta, "Influence of the frequency parameter on extracellular glutamate and $\alpha$-aminobutyric acid in substantia nigra and globus pallidus during electrical stimulation of subthalamic nucleus in rats," Journal of Neuroscience Research, vol. 72, no. 2, pp. 259-267, 2003.

[106] A. D. Dorval, A. M. Kuncel, M. J. Birdno, D. A. Turner, and W. M. Grill, "Deep brain stimulation alleviates parkinsonian bradykinesia by regularizing pallidal activity," Journal of Neurophysiology, vol. 104, no. 2, pp. 911-921, 2010.

[107] Y. Guo, J. E. Rubin, C. C. McIntyre, J. L. Vitek, and D. Terman, "Thalamocortical relay fidelity varies across subthalamic nucleus deep brain stimulation protocols in a data-driven 
computational model," Journal of Neurophysiology, vol. 99, no. 3, pp. 1477-1492, 2008.

[108] A. D. Dorval, G. S. Russo, T. Hashimoto, W. Xu, W. M. Grill, and J. L. Vitek, "Deep brain stimulation reduces neuronal entropy in the MPTP-primate model of Parkinson's disease," Journal of Neurophysiology, vol. 100, no. 5, pp. 2807-2818, 2008.

[109] J. T. Gale, D. C. Shields, F. A. Jain, R. Amirnovin, and E. N. Eskandar, "Subthalamic nucleus discharge patterns during movement in the normal monkey and Parkinsonian patient," Brain Research, vol. 1260, pp. 15-23, 2009.

[110] E. B. Montgomery Jr., "Dynamically coupled, high-frequency reentrant, non-linear oscillators embedded in scale-free basal ganglia-thalamic-cortical networks mediating function and deep brain stimulation effects," Nonlinear Studies, vol. 11, pp. 385-421, 2004.

[111] P. Brown, "Bad oscillations in Parkinson's disease," Journal of Neural Transmission, Supplement, no. 70, pp. 27-30, 2006.

[112] P. Brown and D. Williams, "Basal ganglia local field potential activity: character and functional significance in the human," Clinical Neurophysiology, vol. 116, no. 11, pp. 2510-2519, 2005.

[113] W. D. Hutchison, J. O. Dostrovsky, J. R. Walters et al., "Neuronal oscillations in the basal ganglia and movement disorders: evidence from whole animal and human recordings," Journal of Neuroscience, vol. 24, no. 42, pp. 9240-9243, 2004.

[114] A. A. Kühn, T. Trottenberg, A. Kivi, A. Kupsch, G.-H. Schneider, and P. Brown, "The relationship between local field potential and neuronal discharge in the subthalamic nucleus of patients with Parkinson's disease," Experimental Neurology, vol. 194, no. 1, pp. 212-220, 2005.

[115] A. A. Kühn, F. Kempf, C. Brücke et al., "High-frequency stimulation of the subthalamic nucleus suppresses oscillatory $\beta$ activity in patients with Parkinson's disease in parallel with improvement in motor performance," Journal of Neuroscience, vol. 28, no. 24, pp. 6165-6173, 2008.

[116] N. Fogelson, A. Pogosyan, A. A. Kühn et al., "Reciprocal interactions between oscillatory activities of different frequencies in the subthalamic region of patients with Parkinson's disease," European Journal of Neuroscience, vol. 22, no. 1, pp. 257-266, 2005.

[117] N. Fogelson, A. A. Kühn, P. Silberstein et al., "Frequency dependent effects of subthalamic nucleus stimulation in Parkinson's disease," Neuroscience Letters, vol. 382, no. 1-2, pp. 5-9, 2005.

[118] A. Pogosyan, A. A. Kühn, T. Trottenberg, G. H. Schneider, A. Kupsch, and P. Brown, "Elevations in local gamma activity are accompanied by changes in the firing rate and information coding capacity of neurons in the region of the subthalamic nucleus in Parkinson's disease," Experimental Neurology, vol. 202, no. 2, pp. 271-279, 2006.

[119] G. Paul, T. Reum, W. Meissner et al., "High frequency stimulation of the subthalamic nucleus influences striatal dopaminergic metabolism in the naive rat," NeuroReport, vol. 11, no. 3, pp. 441-444, 2000.

[120] N. Bruet, F. Windels, A. Bertrand, C. Feuerstein, A. Poupard, and M. Savasta, "High frequency stimulation of the subthalamic nucleus increases the extracellular contents of striatal dopamine in normal and partially dopaminergic denervated rats," Journal of Neuropathology and Experimental Neurology, vol. 60, no. 1, pp. 15-24, 2001.

[121] W. Meissner, T. Reum, G. Paul et al., "Striatal dopaminergic metabolism is increased by deep brain stimulation of the subthalamic nucleus in 6-hydroxydopamine lesioned rats," Neuroscience Letters, vol. 303, no. 3, pp. 165-168, 2001.

[122] W. Meissner, D. Harnack, R. Reese et al., "High-frequency stimulation of the subthalamic nucleus enhances striatal dopamine release and metabolism in rats," Journal of Neurochemistry, vol. 85, no. 3, pp. 601-609, 2003.

[123] F. Windels, N. Bruet, A. Poupard et al., "Effects of high frequency stimulation of subthalamic nucleus on extracellular glutamate and GABA in substantia nigra and globus pallidus in the normal rat," European Journal of Neuroscience, vol. 12, no. 11, pp. 4141-4146, 2000.

[124] F. Windels, C. Carcenac, A. Poupard, and M. Savasta, "Pallidal origin of GABA release within the substantia nigra pars reticulata during high-frequency stimulation of the subthalamic nucleus," Journal of Neuroscience, vol. 25, no. 20, pp. 5079-5086, 2005.

[125] P. Salin, C. Manrique, C. Forni, and L. Kerkerian-Le Goff, "High-frequency stimulation of the subthalamic nucleus selectively reverses dopamine denervation-induced cellular defects in the output structures of the basal ganglia in the rat," Journal of Neuroscience, vol. 22, no. 12, pp. 5137-5148, 2002.

[126] J. Henning, D. Koczan, Ä. Glass et al., "Deep brain stimulation in a rat model modulates $\mathrm{TH}$, CaMKIIa and Homer1 gene expression," European Journal of Neuroscience, vol. 25, no. 1, pp. 239-250, 2007.

[127] D. R. Lazzell, R. Belizaire, P. Thakur, D. M. Sherry, and R. Janz, "SV2B regulates synaptotagmin 1 by direct interaction," Journal of Biological Chemistry, vol. 279, no. 50, pp. 5212452131, 2004.

[128] M. H. M. Koken, J. W. Hoogerbrugge, I. Jaspers-Dekker et al., "Expression of the ubiquitin-conjugating DNA repair enzymes HHR6A and B suggests a role in spermatogenesis and chromatin modification," Developmental Biology, vol. 173, no. 1, pp. 119-132, 1996.

[129] P. Kavakebi, B. Hausott, A. Tomasino, S. Ingorokva, and L. Klimaschewski, "The N-end rule ubiquitin-conjugating enzyme, HR6B, is up-regulated by nerve growth factor and required for neurite outgrowth," Molecular and Cellular Neuroscience, vol. 29, no. 4, pp. 559-568, 2005.

[130] V. J. Appleby, S. A. L. Correa, J. K. Duckworth et al., "LTP in hippocampal neurons is associated with a CaMKIImediated increase in GluA1 surface expression," Journal of Neurochemistry, vol. 116, pp. 530-543, 2011.

[131] K. U. Bayer, P. De Koninck, A. S. Leonard, J. W. Hell, and H. Schulman, "Interaction with the NMDA receptor locks CaMKII in an active conformation," Nature, vol. 411, no. 6839, pp. 801-805, 2001.

[132] F. Ango, J. P. Pin, J. C. Tu et al., "Dendritic and axonal targeting of type 5 metabotropic glutamate receptor is regulated by Homer1 proteins and neuronal excitation," Journal of Neuroscience, vol. 20, no. 23, pp. 8710-8716, 2000.

[133] J. Zhang, B. M. Moats-Staats, P. Ye, and A. J. D'Ercole, "Expression of insulin-like growth factor system genes during the early postnatal neurogenesis in the mouse hippocampus," Journal of Neuroscience Research, vol. 85, no. 8, pp. 16181627, 2007.

[134] P. Svenningsson, L. Gunne, and P. E. Andren, "L-DOPA produces strong induction of c-fos messenger RNA in dopamine-denervated cortical and striatal areas of the common marmoset," Neuroscience, vol. 99, pp. 457-468, 2000.

[135] T. Schulte, S. Brecht, T. Herdegen, M. Illert, H. M. Mehdorn, and W. Hamel, "Induction of immediate early gene expression by high-frequency stimulation of the subthalamic 
nucleus in rats," Neuroscience, vol. 138, no. 4, pp. 1377-1385, 2006.

[136] L. H. Shi, D. J. Woodward, F. Luo, K. Anstrom, T. Schallert, and J. Y. Chang, "High-frequency stimulation of the subthalamic nucleus reverses limb-use asymmetry in rats with unilateral 6-hydroxydopamine lesions," Brain Research, vol. 1013, no. 1, pp. 98-106, 2004.

[137] J. Y. Chang, L. H. Shi, F. Luo, and D. J. Woodward, "High frequency stimulation of the subthalamic nucleus improves treadmill locomotion in unilateral 6-hydroxydopamine lesioned rats," Brain Research, vol. 983, no. 1-2, pp. 174-184, 2003.

[138] D. Harnack, W. Meissner, J. A. Jira, C. Winter, R. Morgenstern, and A. Kupsch, "Placebo-controlled chronic highfrequency stimulation of the subthalamic nucleus preserves dopaminergic nigral neurons in a rat model of progressive Parkinsonism," Experimental Neurology, vol. 210, no. 1, pp. 257-260, 2008.

[139] A. L. Spieles-Engemann, M. M. Behbehani, T. J. Collier et al., "Stimulation of the rat subthalamic nucleus is neuroprotective following significant nigral dopamine neuron loss," Neurobiology of Disease, vol. 39, no. 1, pp. 105-115, 2010.

[140] A. L. Spieles-Engemann, T. J. Collier, and C. E. Sortwell, "A functionally relevant and long-term model of deep brain stimulation of the rat subthalamic nucleus: advantages and considerations," European Journal of Neuroscience, vol. 32, no. 7, pp. 1092-1099, 2010.

[141] H. Matsumura, G. Kinoshita, S. Satoh, T. Osaka, and O. Hayaishi, "A novel apparatus that permits multiple routes for infusions and body-fluid collections in a freely-moving animal," Journal of Neuroscience Methods, vol. 57, no. 2, pp. 145-149, 1995.

[142] W. M. Grill and X. F. Wei, "High efficiency electrodes for deep brain stimulation," in Proceedings of the 31st Annual International Conference of the IEEE Engineering in Medicine and Biology Society, pp. 3298-3301, September 2009.

[143] J. Volkmann, E. Moro, and R. Pahwa, "Basic algorithms for the programming of deep brain stimulation in Parkinson's disease," Movement Disorders, vol. 21, supplement 14, pp. S284-S289, 2006.

[144] A. Capozzo, T. Florio, G. Confalone, D. Minchella, P. Mazzone, and E. Scarnati, "Low frequency stimulation of the pedunculopontine nucleus modulates electrical activity of subthalamic neurons in the rat," Journal of Neural Transmission, vol. 116, no. 1, pp. 51-56, 2009.

[145] A. Stefani, M. Pierantozzi, R. Ceravolo, L. Brusa, S. Galati, and P. Stanzione, "Deep brain stimulation of pedunculopontine tegmental nucleus (PPTg) promotes cognitive and metabolic changes: a target-specific effect or response to a low-frequency pattern of stimulation?" Clinical EEG and Neuroscience, vol. 41, no. 2, pp. 82-86, 2010.

[146] P. Mazzone, A. Insola, S. Sposato, and E. Scarnati, "The deep brain stimulation of the pedunculopontine tegmental nucleus," Neuromodulation, vol. 12, no. 3, pp. 191-204, 2009.

[147] N. Jenkinson, D. Nandi, K. Muthusamy et al., "Anatomy, physiology, and pathophysiology of the pedunculopontine nucleus," Movement Disorders, vol. 24, no. 3, pp. 319-328, 2009.

[148] C. Hamani, E. Moro, and A. M. Lozano, "The pedunculopontine nucleus as a target for deep brain stimulation," Journal of Neural Transmission. In press.

[149] W. Thevathasan, P. A. Silburn, H. Brooker et al., "The impact of low-frequency stimulation of the pedunculopontine nucleus region on reaction time in parkinsonism,"
Journal of Neurology, Neurosurgery and Psychiatry, vol. 81, no. 10, pp. 1099-1104, 2010.

[150] P. M. Schweder, C. Joint, P. C. Hansen, A. L. Green, G. Quaghebeur, and T. Z. Aziz, "Chronic pedunculopontine nucleus stimulation restores functional connectivity," NeuroReport, vol. 21, no. 17, pp. 1065-1068, 2010.

[151] I. Osorio, M. G. Frei, B. F. J. Manly, S. Sunderam, N. C. Bhavaraju, and S. B. Wilkinson, "An introduction to contingent (closed-loop) brain electrical stimulation for seizure blockage, to ultra-short-term clinical trials, and to multidimensional statistical analysis of therapeutic efficacy," Journal of Clinical Neurophysiology, vol. 18, no. 6, pp. 533544, 2001.

[152] I. Osorio, M. G. Frei, S. Sunderam et al., "Automated seizure abatement in humans using electrical stimulation," Annals of Neurology, vol. 57, no. 2, pp. 258-268, 2005.

[153] K. N. Fountas, J. R. Smith, A. M. Murro, J. Politsky, Y. D. Park, and P. D. Jenkins, "Implantation of a closed-loop stimulation in the management of medically refractory focal epilepsy: a technical note," Stereotactic and Functional Neurosurgery, vol. 83, no. 4, pp. 153-158, 2005.

[154] J. R. Smith, K. N. Fountas, A. M. Murro et al., "Closed-loop stimulation in the control of focal epilepsy of insular origin," Stereotactic and Functional Neurosurgery, vol. 88, no. 5, pp. 281-287, 2010.

[155] C. Hauptmann, J. C. Roulet, J. J. Niederhauser et al., "External trial deep brain stimulation device for the application of desynchronizing stimulation techniques," Journal of Neural Engineering, vol. 6, no. 6, Article ID 066003, 2009.

[156] S. Breit, T. Wächter, L. Schöls et al., "Effective thalamic deep brain stimulation for neuropathic tremor in a patient with severe demyelinating neuropathy," Journal of Neurology, Neurosurgery and Psychiatry, vol. 80, no. 2, pp. 235-236, 2009.

[157] K. D. Foote and M. S. Okun, "Ventralis intermedius plus ventralis oralis anterior and posterior deep brain stimulation for posttraumatic Holmes tremor: two leads may be better than one: technical note," Neurosurgery, vol. 56, no. 4, Article ID E445, 2005.

[158] S. G. Jeong, M. K. Lee, W. H. Lee, and C. G. Ghang, "Deep brain stimulation of the subthalamic area for dystonic tremor," Journal of Korean Neurosurgical Society, vol. 45, no. 5, pp. 303-305, 2009.

[159] S. Peker, U. Isik, Y. Akgun, and M. Ozek, "Deep brain stimulation for Holmes' tremor related to a thalamic abscess," Child's Nervous System, vol. 24, no. 9, pp. 1057-1062, 2008.

[160] E. Moro, A. E. Lang, A. P. Strafella et al., "Bilateral globus pallidus stimulation for Huntington's disease," Annals of Neurology, vol. 56, no. 2, pp. 290-294, 2004.

[161] Y. Temel, C. Cao, R. Vlamings et al., "Motor and cognitive improvement by deep brain stimulation in a transgenic rat model of Huntington's disease," Neuroscience Letters, vol. 406, no. 1-2, pp. 138-141, 2006.

[162] A. W. Laxton, D. F. Tang-Wai, M. P. McAndrews et al., "A phase i trial of deep brain stimulation of memory circuits in Alzheimer's disease," Annals of Neurology, vol. 68, no. 4, pp. 521-534, 2010.

[163] S. Namba, Y. Nakao, and Y. Matsumoto, "Electrical stimulation of the posterior limb of the internal capsule for treatment of thalamic pain," Applied Neurophysiology, vol. 47, no. 3, pp. 137-148, 1984.

[164] A. Franzini, G. Messina, C. Marras et al., "Poststroke fixed dystonia of the foot relieved by chronic stimulation of the posterior limb of the internal capsule: case report," Journal of Neurosurgery, vol. 111, no. 6, pp. 1216-1219, 2009. 
[165] R. Levy, T. R. Deer, and J. Henderson, "Intracranial neurostimulation for pain control: a review," Pain Physician, vol. 13, no. 2, pp. 157-165, 2010.

[166] C. Hamani, J. M. Schwalb, A. R. Rezai, J. O. Dostrovsky, K. D. Davis, and A. M. Lozano, "Deep brain stimulation for chronic neuropathic pain: long-term outcome and the incidence of insertional effect," Pain, vol. 125, no. 1-2, pp. 188-196, 2006.

[167] M. Rahman, M. M. Abd-El-Barr, V. Vedam-Mai et al., "Disrupting abnormal electrical activity with deep brain stimulation: is epilepsy the next frontier?" Neurosurgical Focus, vol. 29, no. 2, p. E7, 2010.

[168] R. Fisher, V. Salanova, T. Witt et al., "Electrical stimulation of the anterior nucleus of thalamus for treatment of refractory epilepsy," Epilepsia, vol. 51, no. 5, pp. 899-908, 2010.

[169] B. D. Greenberg, D. A. Malone, G. M. Friehs et al., "Threeyear outcomes in deep brain stimulation for highly resistant obsessive-compulsive disorder," Neuropsychopharmacology, vol. 31, no. 11, pp. 2384-2393, 2006.

[170] B. D. Greenberg, L. A. Gabriels, D. A. Malone et al., "Deep brain stimulation of the ventral internal capsule/ventral striatum for obsessive-compulsive disorder: worldwide experience," Molecular Psychiatry, vol. 15, no. 1, pp. 64-79, 2010.

[171] W. I. A. Haynes and L. Mallet, "High-frequency stimulation of deep brain structures in obsessive-compulsive disorder: the search for a valid circuit," European Journal of Neuroscience, vol. 32, no. 7, pp. 1118-1127, 2010.

[172] H. S. Mayberg, A. M. Lozano, V. Voon et al., "Deep brain stimulation for treatment-resistant depression," Neuron, vol. 45, no. 5, pp. 651-660, 2005.

[173] A. M. Lozano, H. S. Mayberg, P. Giacobbe, C. Hamani, R. C. Craddock, and S. H. Kennedy, "Subcallosal cingulate gyrus deep brain stimulation for treatment-resistant depression," Biological Psychiatry, vol. 64, no. 6, pp. 461-467, 2008.

[174] C. Hamani and J. N. Nóbrega, "Deep brain stimulation in clinical trials and animal models of depression," European Journal of Neuroscience, vol. 32, no. 7, pp. 1109-1117, 2010.

[175] N. D. Schiff, J. T. Giacino, K. Kalmar et al., "Behavioural improvements with thalamic stimulation after severe traumatic brain injury," Nature, vol. 448, no. 7153, pp. 600-603, 2007.

[176] A. Costa, G. A. Carlesimo, C. Caltagirone et al., "Effects of deep brain stimulation of the peduncolopontine area on working memory tasks in patients with Parkinson's disease," Parkinsonism and Related Disorders, vol. 16, no. 1, pp. 64-67, 2010.

[177] C. Moreau, L. Defebvre, D. Devos et al., "STN versus PPNDBS for alleviating freezing of gait: toward a frequency modulation approach?" Movement Disorders, vol. 24, pp. 2164-2166, 2009.

[178] R. Fuentes, P. Petersson, W. B. Siesser, M. G. Caron, and M. A. L. Nicolelis, "Spinal cord stimulation restores locomotion in animal models of Parkinson's disease," Science, vol. 323, no. 5921, pp. 1578-1582, 2009.

[179] R. Fuentes, P. Petersson, and M. A. L. Nicolelis, "Restoration of locomotive function in Parkinson's disease by spinal cord stimulation: mechanistic approach," European Journal of Neuroscience, vol. 32, no. 7, pp. 1100-1108, 2010.

[180] W. Thevathasan, P. Mazzone, A. Jha et al., "Spinal cord stimulation failed to relieve akinesia or restore locomotion in parkinson disease," Neurology, vol. 74, no. 16, pp. 1325-1327, 2010.

[181] F. Cohadon and E. Richer, "Deep brain stimulation in patients with post traumatic persistent vegetative state. 25 cases," Neurochirurgie, vol. 39, no. 5, pp. 281-292, 1993.
[182] T. Yamamoto, Y. Katayama, K. Kobayashi, H. Oshima, C. Fukaya, and T. Tsubokawa, "Deep brain stimulation for the treatment of vegetative state," European Journal of Neuroscience, vol. 32, no. 7, pp. 1145-1151, 2010.

[183] T. M. Dawson, H. S. Ko, and V. L. Dawson, "Genetic animal models of Parkinson's disease," Neuron, vol. 66, no. 5, pp. 646-661, 2010.

[184] S. von Hörsten, I. Schmitt, H. P. Nguyen et al., "Transgenic rat model of Huntington's disease," Human Molecular Genetics, vol. 12, no. 6, pp. 617-624, 2003.

[185] K. Grundmann, B. Reischmann, G. Vanhoutte et al., "Overexpression of human wildtype torsinA and human deltaGAG torsin A in a transgenic mouse model causes phenotypic abnormalities," Neurobiology of Disease, vol. 27, no. 2, pp. 190-206, 2007.

[186] V. Gradinaru, M. Mogri, K. R. Thompson, J. M. Henderson, and K. Deisseroth, "Optical deconstruction of parkinsonian neural circuitry," Science, vol. 324, no. 5925, pp. 354-359, 2009.

[187] W. Asaad and E. Eskandar, "The movers and shakers of deep brain stimulation," Nature Medicine, vol. 14, no. 1, pp. 17-19, 2008.

[188] M. A. L. Nicolelis and M. A. Lebedev, "Principles of neural ensemble physiology underlying the operation of brainmachine interfaces," Nature Reviews Neuroscience, vol. 10, no. 7, pp. 530-540, 2009. 


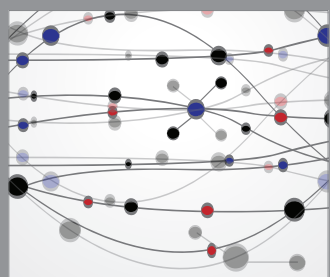

The Scientific World Journal
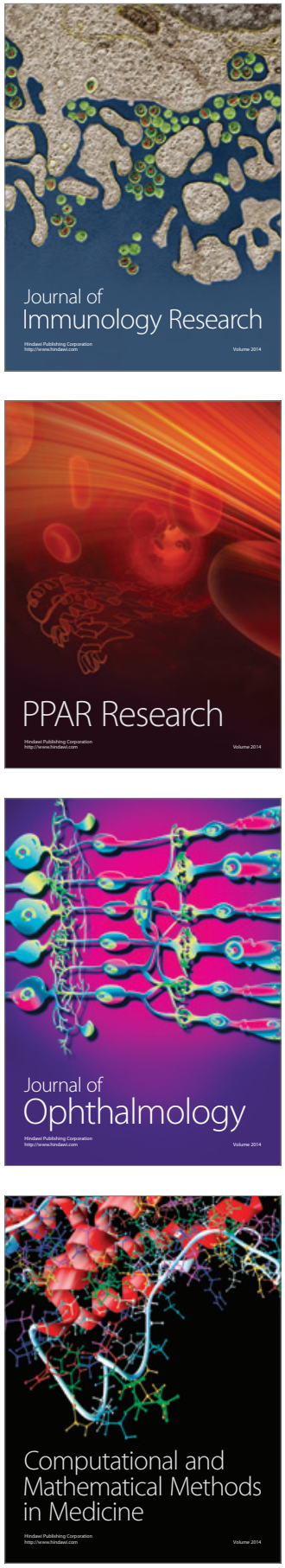

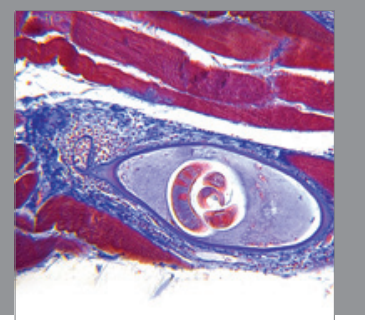

Gastroenterology

Research and Practice
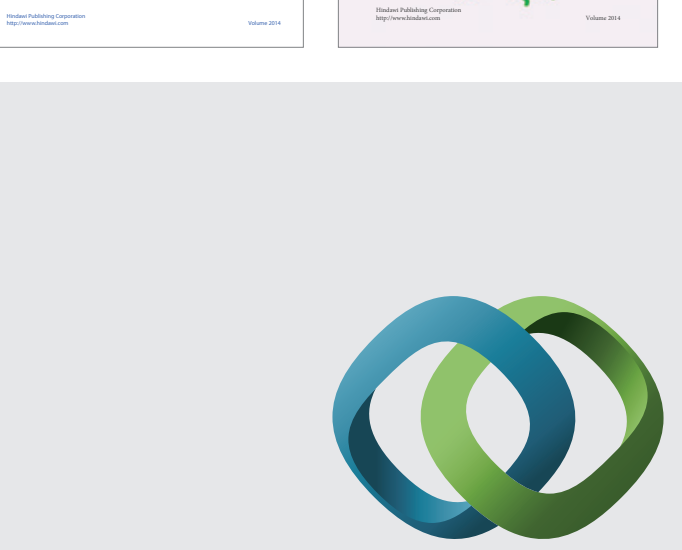

\section{Hindawi}

Submit your manuscripts at

http://www.hindawi.com
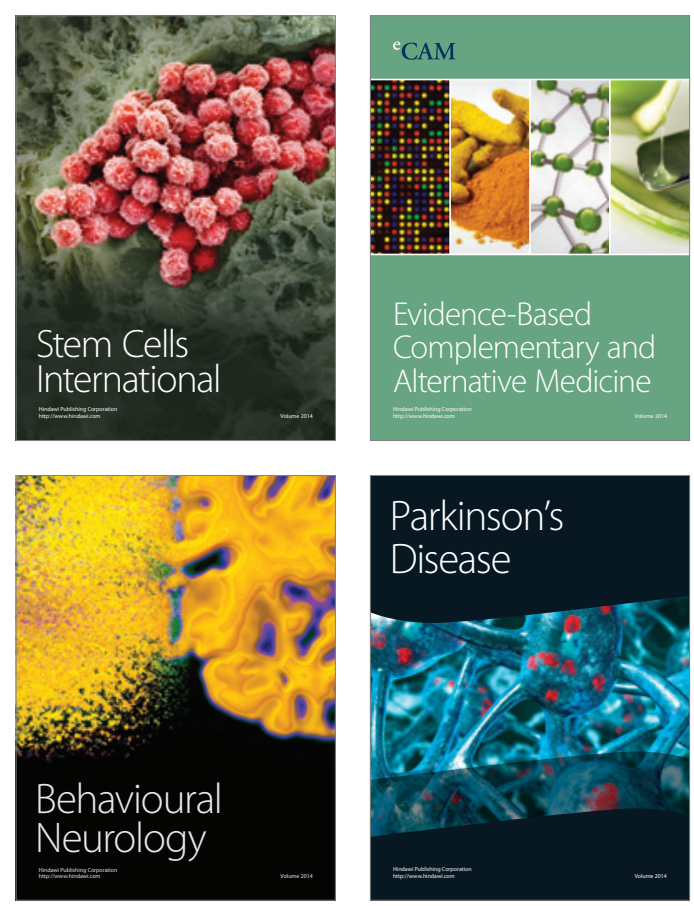

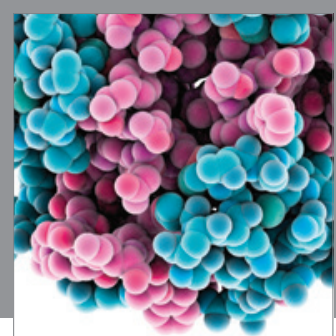

Journal of
Diabetes Research

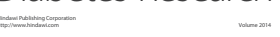

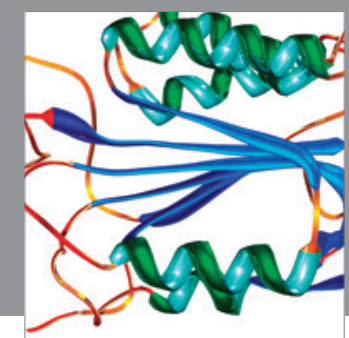

Disease Markers
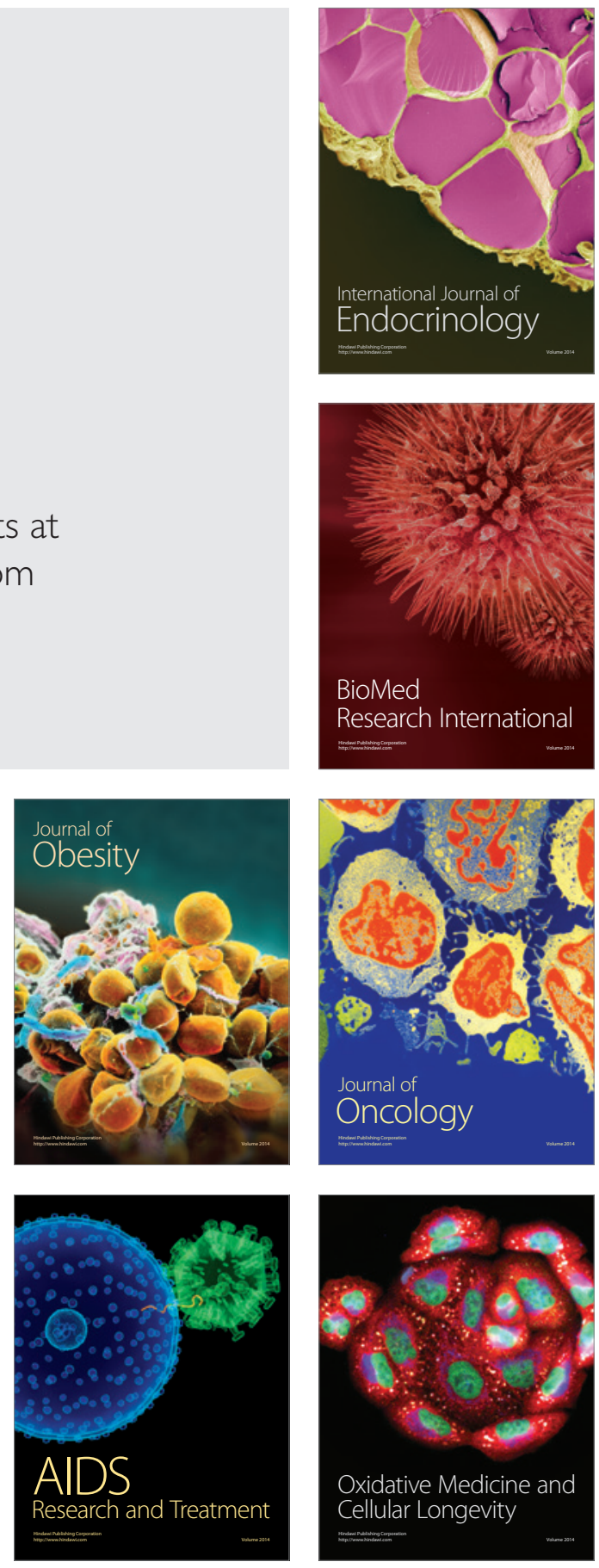